\title{
Material Removal and Specific Energy in the Dynamic Scratching of Gamma Titanium Aluminides
}

\author{
Hong Wang, Hua-Tay Lin and Andrew A. Wereszczak \\ Materials Science and Technology Division \\ Oak Ridge National Laboratory, Oak Ridge, TN 37831, USA
}

November 30, 2006 


\section{TABLE OF CONTENTS}

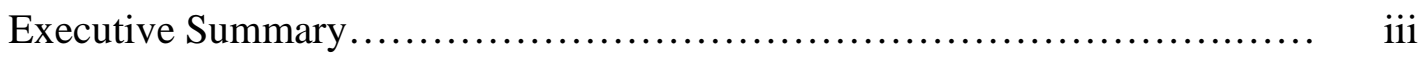

List of Tables ......................................................... iv

List of Figures........................................................ v

1 Introduction.............................................................. 1

2 Experimental Approaches.............................................. 1

3 Experimental Results.................................................. 7

3.1 Material Removal............................................ 7

3.2 Scratch Forces.................................................. 12

3.3 Scratch Groove Profiles....................................... 12

3.4 Overall Frictional Coefficient (OFC) ........................... 16

3.5 Degree of Wear............................................... 16

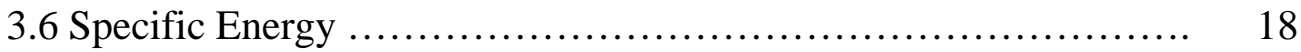

3.7 Instantaneous Specific Energy and Scratch Resistance............... 18

3.8 Scratch Hardness................................................. 22

4 Analyses.............................................................. 22

4.1 Material Removal Mechanism................................. 22

4.2 Specific Energy, Scratch Resistance and Scratch Hardness as a

Function of Groove Depth......................................... 25

4.3 Scratch Hardness as Related to Indentation Hardness ............... 32

4.4 Two-parameter Model Analysis on Cutting Pressure and

Scratch Hardness.................................................... 32

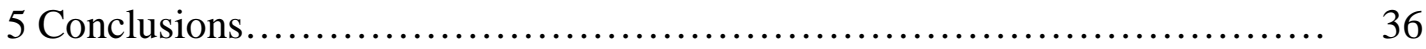

ACKNOWLEDGMENTS.................................................. 37

REFERENCES............................................................. 37 


\section{Executive Summary}

Mechanical responses of three gamma titanium aluminides (TiAls) (denoted as Alloy A, Alloy B and Alloy C) subjected to dynamic scratching were studied by using a single-grit pendulum (rotating) scratch tester. The maximum depth of groove was $\sim 0.07$ $\mathrm{mm}$, and the scratch velocity was $\sim 1.0 \mathrm{~m} / \mathrm{s}$. Normal and tangential forces were monitored. The material removal mechanisms were examined using a scanning electron microscope (SEM) and the scratches were measured by using a laser profilometer. The mechanical properties of the tested TiAls were characterized by the instantaneous specific energy, scratch resistance and scratch hardness as related to the groove depth. Extensive thermal softening was observed in the dynamic scratch test of the TiAls, which facilitated both the detachment of developing chips and pile-up of material on side ridges. Sizable fractures were observed in the transverse direction in the tested TiAls; these fractures tended to participate in the chip formation, depending on the microstructure of the $\mathrm{TiAl}$ and the size of the scratch groove.

Specific energy and scratch hardness are depth-dependent to various degrees for the TiAls tested. The material removal might be subjected to different mechanisms, but the overall material response can be effectively characterized by the HEM (Hwang, Evans and Malkin) model and the PSR (proportional specimen resistance) model. The depthindependent specific energy and scratch hardness can be used to screen candidate materials for the applications that are scratch-dominated versus impact-dominated. Among the three tested TiAls, the TiAl with larger colony or grain size exhibits a stronger capability of energy dissipation during material removal (higher depthindependent specific energy), while the TiAl with smaller colony size shows a higher resistance to indentation (higher depth-independent scratch hardness).

The observations and conclusions in this study can serve as a base line for the further characterization of the related materials under the service temperature as recommended for diesel engine. 


\section{LIST OF TABLES}

Table

$\underline{\text { Page }}$

1 Compositions and microstructures of the tested gamma titanium aluminides ...........................................................

2 Physical and mechanical properties of the tested gamma titanium aluminides.........................................................

3 Two-parameter model analysis of the tested gamma titanium aluminides........................................................ 35 


\section{LIST OF FIGURES}

Figure

$\underline{\text { Page }}$

1 Components of the single-grit pendulum scratch tester: (a) specimen fixture mounted on a rigid platform that is operated by a handle (not shown); (b) pendulum, equipped with a positioning micrometer on the top, is driven by a piston that is pneumatically operated by high pressure gas...................................................

2 Optical micrographs of polished and chemically etched (a) Alloy A,

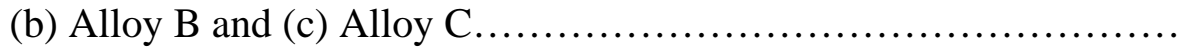

3 SEM micrographs of scratched (a) Alloy A (cd0102), (b) Alloy B (cd0301) and (c) Alloy C (cd0202). Scratches run from left to right. The micrographs were taken after chemical etching...................

$4 \quad$ SEM micrographs corresponding to a scratch (cd0102, scratch from left to right, chemically etched) in Alloy A showing (a) deformed lamellar layers with inter-lamellar cracking; (b) fractured groove surface with secondary inter-colony cracks; (c) conjugate shear lines ahead of a pile-up; (d) pitting with dense voids along the fracture.

5 SEM micrographs corresponding to a scratch (cd0301, from left to right, chemically etched) in Alloy B showing (a) deformed lamellae with associated crack; (b) deformed lamellae at large angle with associated crack; (c) deep fracture; (d) shallow pitting.................

6 SEM micrographs corresponding to a scratch (cd0202, scratch from left to right, chemically etched) in Alloy $\mathrm{C}$ showing (a) cleavage on the groove; (b) deformed lamellae with associated inter-lamellar crack; (c) partially detached chipping formed by cleavage; (d) fracture surface as a result of partial detached chipping with dense voids........

$7 \quad$ Force profiles of typical scratches on (a) Alloy A, (b) Alloy B and (c) Alloy C.........................................................

8 Sketch of scratch sectional areas at a given depth of groove; scratch longitudinal axis is perpendicular to the page.

$9 \quad$ Variations of groove depth and sectional areas of typical scratches on (a) Alloy A, (b) Alloy B and (c) Alloy C........................ 15 
10 Variations of OFC (overall friction coefficient) and degree of wear on (a) Alloy A, (b) Alloy B and (c) Alloy C....................... 17

11 Variations of progressive specific energy and instantaneous specific energy on (a) Alloy A, (b) Alloy B and (c) Alloy C.................. 20

12 Variations of scratch resistance and scratch hardness on (a) Alloy A, (b) Alloy B and (c) Alloy C.................................. 21

13 Specific energy as a function of groove depth for (a) Alloy A, (b)

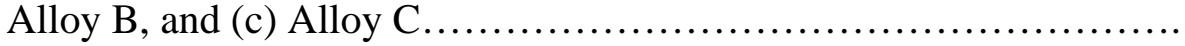

14 Scratch resistance and scratch hardness as a function of groove depth for (a) Alloy A, (b) Alloy B, and (c) Alloy C.................... 28

15 Averaged pressures as a function of groove depth for (a) Alloy A, (b) Alloy B and (c) Alloy C........................................

16 Analysis of specific energy and scratch hardness as a function of groove depth for (a) Alloy A, (b) Alloy B, and (c) Alloy C............. 


\section{INTRODUCTION}

Gamma titanium aluminide ( $\mathrm{TiAl}$ ) has attracted extensive attention during the last two decades [1-8]. It exhibits a higher specific strength, higher specific Young's modulus and lower coefficient of thermal expansion than the nickel-based super alloys. Moreover, it can be readily made through the use of the conventional manufacturing methods. The recent usage of $\mathrm{TiAl}$ for turbocharger wheels has triggered strong interest in the automotive community [9]. It was also demonstrated that TiAl valves can result in a 8\% power increase over stainless steel valves due to the increase in allowable rpm [5]. A comprehensive understanding of the wear mechanism of gamma TiAl remains to be developed; on the other hand, research has been conducted concerning the creep rate and strength as a function of temperature [2-4, 10-14]. As the target components (e.g., exhaust valves) are generally exposed to high-speed reciprocal movement in the service, the response of TiAls to such conditions needs to be appropriately examined before they are implemented in the engine system.

This report focuses on one of the wear aspects of TiAl valves; namely, abrasive wear at room temperature. We used a newly-developed single-grit pendulum scratch technique to measure the dynamic abrasion due to sliding contact. This approach is employed because of its advantages over the traditional sliding scratch technique in characterizing the materials removal mechanisms [15-18]. In the following, the unique features of the experimental apparatus will be given, the experimental results on three TiAls that have potential application in diesel engines will be presented, and finally the analyses of the results with special respect to the material removal and energy dissipation will be given.

\section{EXPERIMENTAL APPROACHES}

The principle of experimental scratch-testing technique has been described elsewhere $[15,16]$. The apparatus used in this study for the single-grit pendulum scratch test (developed at Michigan Technological University, Houghton, MI) [17] consists of a rigid platform on which the specimen fixture is mounted and includes translation 


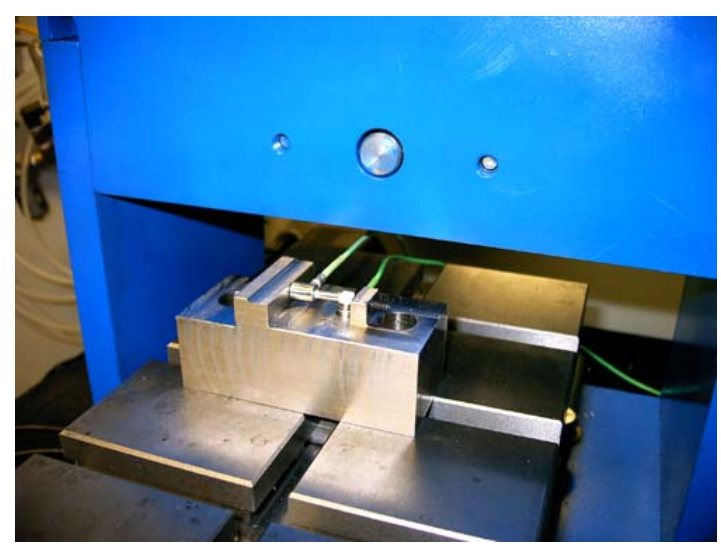

(a)

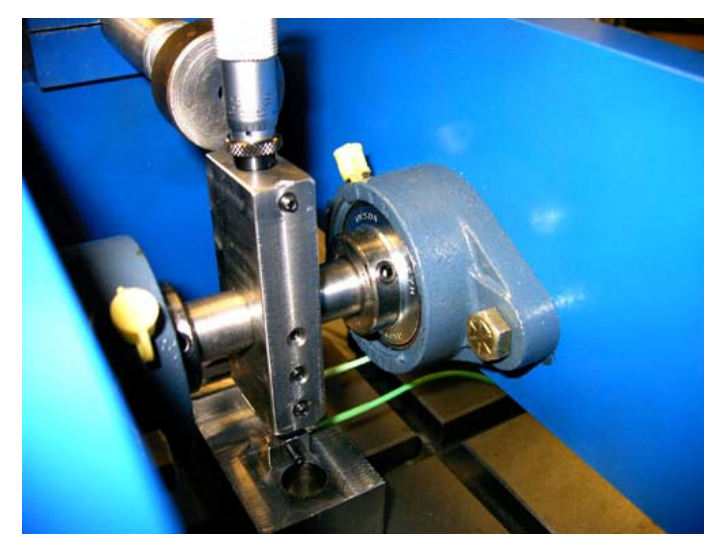

(b)

Fig. 1 Components of the single-grit pendulum scratch tester: (a) specimen fixture mounted on a rigid platform that is operated by a handle (not shown); (b) pendulum, equipped with a positioning micrometer on the top, is driven by a piston that is pneumatically operated by high pressure gas.

capability for ease of specimen mounting and positioning (Fig. 1 (a)). A micrometer is also mounted on top of the pendulum such that its shaft can be located directly on the top of the diamond tool. One can thus measure the tool position with the micrometer, while adjusting the tool in the center of the pendulum (Fig.1 (b)). The signal from two load cells is outputted to a digitizer (NI5102) via charge amplifiers and data acquired by a LabVIEW program (National Instruments, Austin, TX). Conical diamond tools used (J \& L Industrial Supply, Pittsburgh, PA) have a $90^{\circ}$ included angle, a tip radius of $\sim 5 \mu \mathrm{m}$ and shank sizes of $6.35 \mathrm{~mm}$ diameter x $50.8 \mathrm{~mm}$ length.

Three kinds of TiAls were examined and tested because of their potential application to diesel engines. These materials were denoted as Alloy A, Alloy B, and 
Alloy C. The analyzed compositions of these alloys are listed in Table 1, of which Alloy $\mathrm{B}$ and $\mathrm{C}$ were cast under a HIP (hot isostatic pressing) condition and Alloy C was grainrefined by the addition of the TiB2 particles. As shown in optical micrographs in Fig. 2 (a) to (c), Alloy A had a duplex structure consisting of 50\% lamellar structure and 150 $\mu \mathrm{m}$ colony size. Alloy B had a fully lamellar structure and $~ 400 \mu \mathrm{m}$ colony size. Alloy C was also fully lamellar, but the colony size was much smaller ( $100 \mu \mathrm{m})$. In addition, Alloy B exhibited a higher thermal conductivity and a higher failure elongation, and Alloy C exhibited a higher ultimate tensile strength (UTS) under room temperature (Table 2).

A number of test cubes $6.35 \mathrm{~mm}$ in size were cut from castings of each TiAl alloy. One surface of each cube was then polished to a $0.25 \mu \mathrm{m}$ finish. During each scratch test, the tool position was generally adjusted such that the finished scratch had a length of $\sim 3 \mathrm{~mm}$, and that corresponded to a loading pulse of $\sim 3 \mathrm{~ms}$ and a speed of $1 \mathrm{~m} / \mathrm{s}$ in the scratch (horizontal) direction. In the direction normal to the specimen surface, the controlled scratch exhibited a penetration rate of $0.05 \mathrm{~m} / \mathrm{s}$ considering the maximum depth of groove of $0.070 \mathrm{~mm}$. On each polished surface, two to three parallel scratches were made, and the specimen was carefully positioned between tests so that interaction between scratches was avoided.

\begin{tabular}{l|l|l}
\hline Alloy & Composition $^{*}$ & Microstructre \\
\hline Alloy A & Ti-48Al-2Nb-0.7Cr-0.3Si & Non-HIP, partial lamellar, $\sim 150 \mu$ m colony size \\
\hline Alloy B & Ti-48Al-2Nb-0.7Cr-0.3Si & HIP, fully lamellar, $\sim 400 \mu$ m colony size \\
\hline Alloy C & Ti-45Al-2Nb-2Mn + 0.8vol\%TiB2 & HIP, fully lamellar, $\sim 100 \mu$ m colony size \\
\hline
\end{tabular}

${ }^{*}$ Provided by Nan Yang at Caterpillar, Inc.

Table 1 Compositions and microstructures of the tested gamma titanium aluminides 


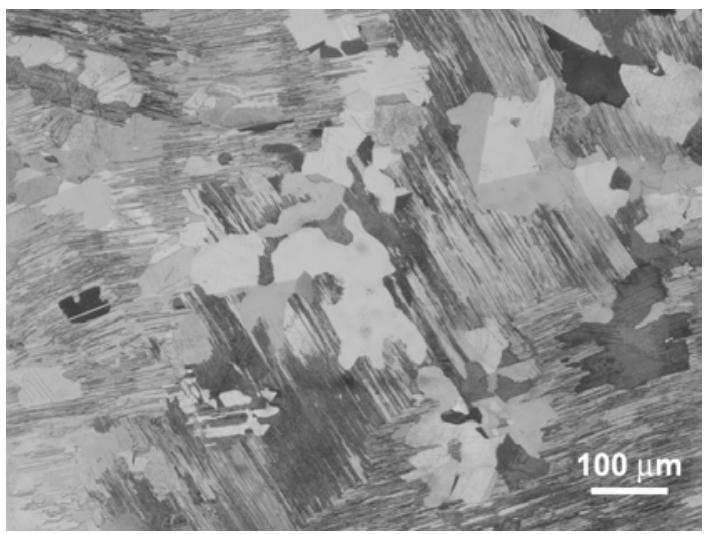

(a)

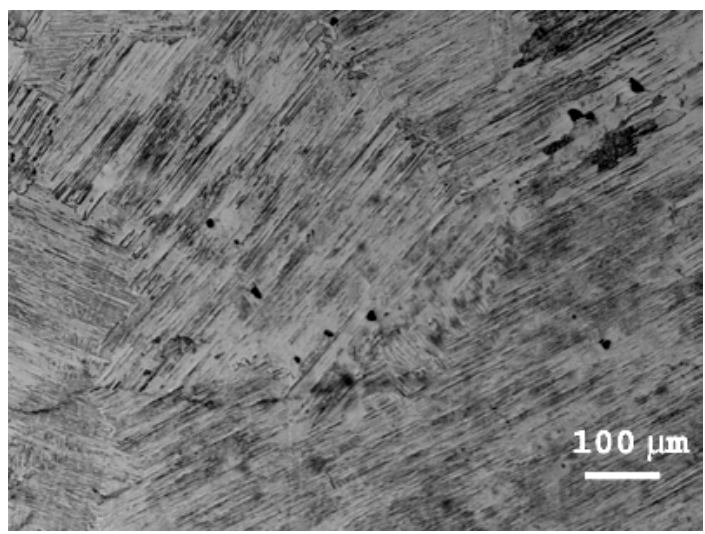

(b)

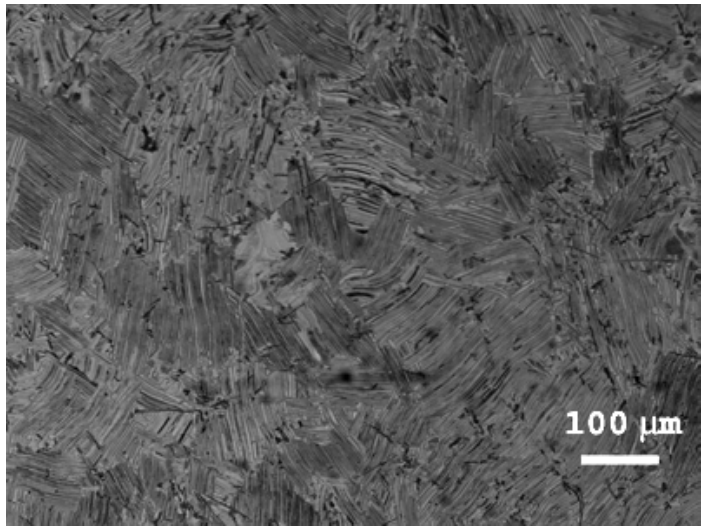

(c)

Fig. 2. Optical micrographs of polished and chemically etched (a) Alloy A, (b) Alloy B and (c) Alloy C. 


\begin{tabular}{|c|c|c|c|c|c|c|c|c|c|c|c|c|}
\hline \multirow[t]{2}{*}{ Materials } & \multirow[t]{2}{*}{$\begin{array}{l}\text { Density } \\
\rho \\
\left(\mathrm{Kg} / \mathrm{m}^{3}\right)\end{array}$} & \multirow[t]{2}{*}{$\begin{array}{l}E^{*} \\
\text { (GPa) }\end{array}$} & \multirow[t]{2}{*}{$v^{*}$} & \multicolumn{2}{|c|}{$\begin{array}{l}\text { Specific } \\
\text { heat }^{\dagger} \\
\text { c }\left(\mathbf{J} / \mathbf{K g}^{\mathbf{0}} \mathbf{C}\right)\end{array}$} & \multicolumn{2}{|c|}{$\begin{array}{l}\text { Thermal } \\
\text { conductivity }^{\ddagger} \\
\text { K }\left(W / \mathbf{m}^{\circ} \mathrm{C}\right)\end{array}$} & \multicolumn{2}{|c|}{$\begin{array}{l}\text { Ultimate } \\
\text { tensile } \\
\text { strength }{ }^{\pi} \\
\sigma_{\text {ult }}(\mathrm{MPa}) \\
\end{array}$} & \multicolumn{2}{|c|}{$\begin{array}{l}\text { Failure } \\
\text { elongation } \\
(\%)\end{array}$} & \multirow{2}{*}{$\begin{array}{l}\text { Compressive } \\
\text { yield } \\
\text { strength }^{\S} \\
\text { Y (MPa) }\end{array}$} \\
\hline & & & & $40^{\circ} \mathrm{C}$ & $820^{\circ} \mathrm{C}$ & $\mathrm{RT}$ & $800^{\circ} \mathrm{C}$ & RT & $800^{\circ} \mathrm{C}$ & $\mathrm{RT}$ & $800^{\circ} \mathrm{C}$ & \\
\hline Alloy A & 3,915 & 173 & 0.28 & 602 & 785 & 16.8 & 28.7 & - & - & - & - & 727 \\
\hline Alloy B & 3,889 & 170 & 0.23 & 609 & 786 & 17.2 & 31.0 & 564.0 & 597.1 & 0.60 & 22.2 & 820 \\
\hline Alloy C & 3,979 & 164 & 0.26 & 589 & 776 & 11.2 & 22.4 & 696.7 & 500.2 & 0.49 & 4.9 & 1,130 \\
\hline
\end{tabular}

* Young's modulus and Poisson's ratio are based on RUS (resonance ultrasonic spectroscopy) measurements by ORNL's Kurt E. Johanns;

† Specific heat is based on differential scanning calorimeter measurements conducted by ORNL's Wallace Porter;

‡ The thermal conductivities of alloy A and B were measured by ORNL’s Hsin Wang using laser flash technique; those of alloy $\mathrm{C}$ were provided by Nan Yang at Caterpillar, Inc.;

" Provided by Nan Yang at Caterpillar, Inc.;

${ }^{\S}$ Calculated according to the modified Johnson model.

Table 2 Physical and mechanical properties of the tested gamma titanium aluminides 
Eight to ten scratches were made for each TiAl alloy, and only representative scratches were selected and used in the consequent analyses based on the quality of force signals and scratch appearance. The selected scratches in each group were observed using an optical microscope (Nikon MM-11, Tokyo, Japan) and a scanning electronic microscope (SEM) (Hitachi S4100, San Jose, CA). In order to effectively resolve the microstructures and scratch-induced damage, some of the scratched surfaces were studied under both un-etched and etched conditions; and the etchings were conducted

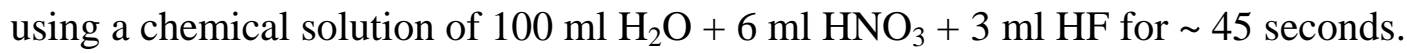

Each scratch was also measured after the test with a laser profilometer (Rodenstock RM-600, Munich, Germany). The laser sensor had a resolution of $0.002 \mu \mathrm{m}$ and a maximum sensing range of $+/-300 \mu \mathrm{m}$ in the depth direction $(\mathrm{z})$. Before the measurement, each scratch was longitudinally aligned with the indexing direction of the laser beam. Scans were performed in the direction (y) transverse to the scratch length with a resolution of $<1 \mu \mathrm{m}$, and the spacing of scanning (resolution) in the longitudinal direction (x) was set at 8 to $10 \mu \mathrm{m}$. The scanning range for each measurement was generally set large enough to cover the surrounding influenced zone so that the base level could be defined.

Dynamic indentation tests on each TiAl alloy were also performed by using a dynamic indentation system [19, 20] (developed also at Michigan Technological University, Houghton, MI) to relate responses of the materials under different loading conditions. The system employs an incidental steel bar with momentum trap capability to load the attached Vickers indenter in such a manner that the obtained loading pulse can be as short as $100 \mu$ s [21], depending on the length of projectile. The peak indentation load was controlled in the same range as that in scratch and eight to ten indents were made for each TiAl. The generated penetration rate was about $0.3 \mathrm{~m} / \mathrm{s}$, which is higher than that in scratch, but one can compare both results since the strain under a Vickers indenter is lower than that under a $90^{\circ}$ conic indenter. 


\section{EXPERIMENTAL RESULTS}

\subsection{Material Removal}

Three typical scratches made in the respective TiAl alloys are respectively shown in Fig. 3 (a) to (c) where all of the scratch directions run from left to right and cd0102 in Alloy A, cd0301 in Alloy B, cd0202 in Alloy C denote the serial numbers of conic dynamic scratch (similar notations are used throughout the report). Overall, the groove surfaces of the scratches in three TiAl alloys appear to have maintained a certain degree of integrity with clear surface contours, which is distinctly different from those of scratches on brittle materials [16, 17, 22]. Side ridges are developed with appreciable pile-up, especially over the wide middle region of scratch. Frequent fractures are found in the transverse direction over the middle region of the scratch, some of which are sizable and run into the bottom of the groove. For Alloy A and B, no shallow lateral fractures were developed, which have been observed to occur in pure titanium. As a result of that, the transverse fractures (though sizable) did not have an opportunity to form a chip on the side ridge. However, in Alloy C, the lateral fractures were developed on the sides of the scratch as a consequence of cleavage; thus the material removal is enhanced that would increase the degree of wear.

The enlarged areas of the scratch revealed many additional features near the side ridges and the bottom of groove. For scratches in Alloy A, several features are observed: severely bent lamellar layers, Fig. 4 (a), primary fracture and secondary inter-colony fracture, Fig. 4 (b), conjugate shear lines with a pile-up, Fig. 4 (c), and pitting on the groove surface formed by the local shallow fracture and transverse fracture, Fig. 4 (d). Micro voids in the groove surface might be from the chemical etching as the un-etched specimen did not show such a density of voids.

It is interesting to see that, on the left side of tool, an array of pile-ups was created over the middle region of the scratch when the tool traversed a large colony in Alloy B as shown Fig. 3 (b). The lamellar layer of the colony formed an acute angle with the tool direction and that facilitated the formation of the pile-up on the left side. The enlarged areas of the scratch revealed a bulge, Fig. 5 (a), significant inter-layer fractures as well as bent lamellar layers, Fig. 5 (b), deep transverse fracture, Fig. 5(c) and pitting formed by 
the intersection of local crack and lamellar layer, Fig. 5 (d). Again, extensive micro-voids were distributed around the groove, which may again be attributed to the chemical etching.

Some different features were revealed on the scratch in Alloy C in Fig. 3(c) as illustrated in Fig. 6 (a) to (d). Beside the bent lamellar layer, considerable lateral fractures and partially detached chips can be seen. In some cases, large lateral cleavages appear to extend into the bottom of the groove.

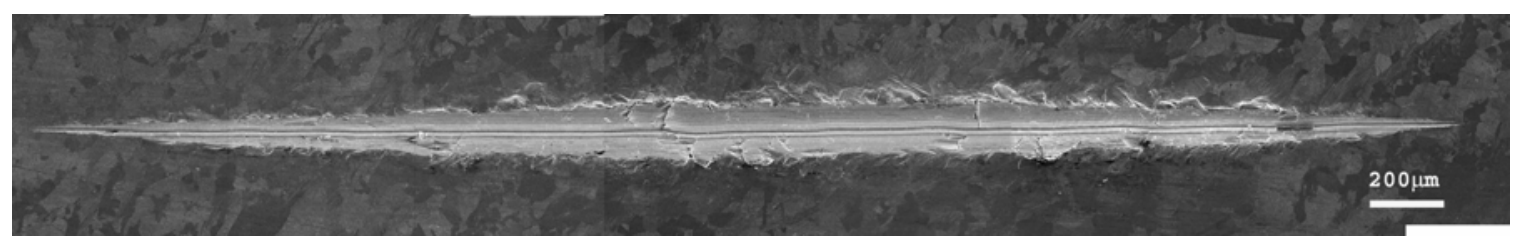

(a)

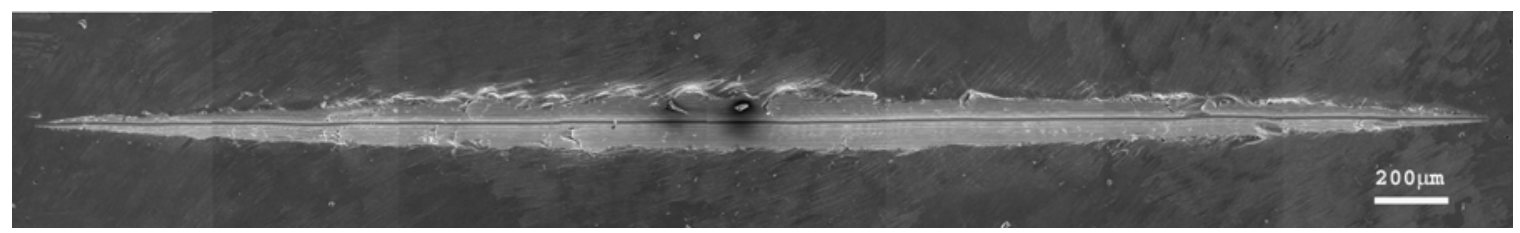

(b)

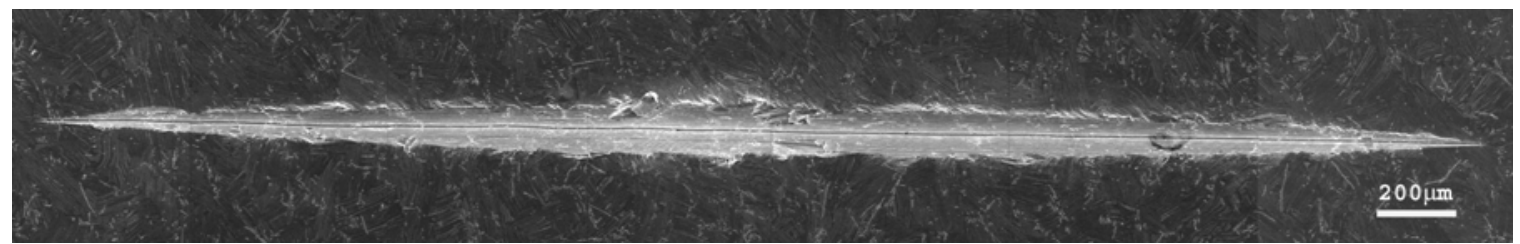

(c)

Fig. 3 SEM micrographs of scratched (a) Alloy A (cd0102), (b) Alloy B (cd0301) and (c) Alloy C (cd0202). Scratches run from left to right. The micrographs were taken after chemical etching. 


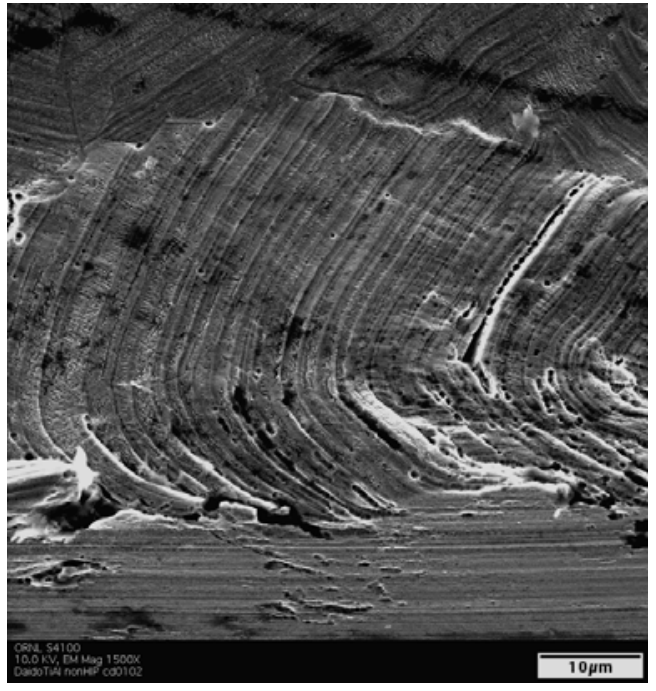

(a)

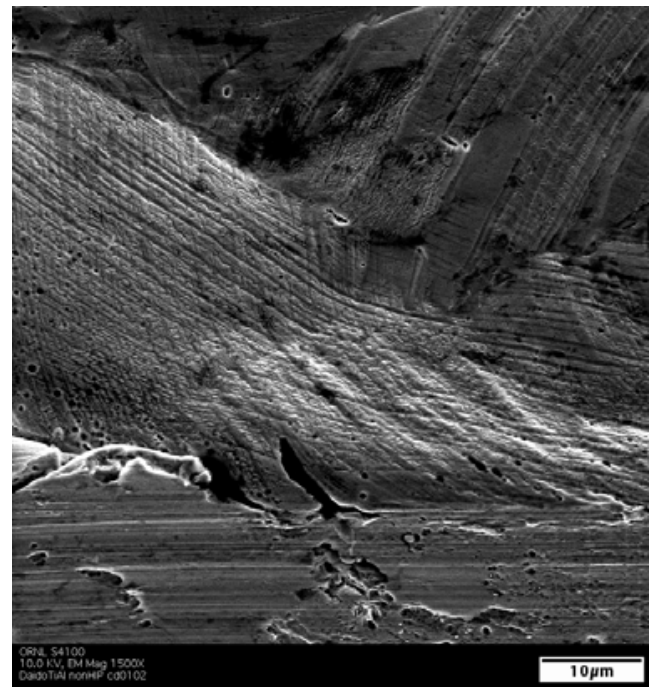

(c)

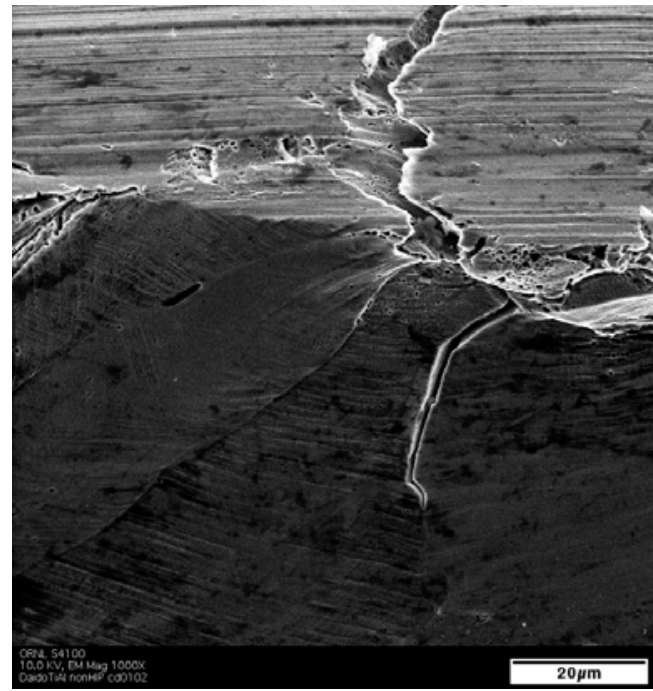

(b)

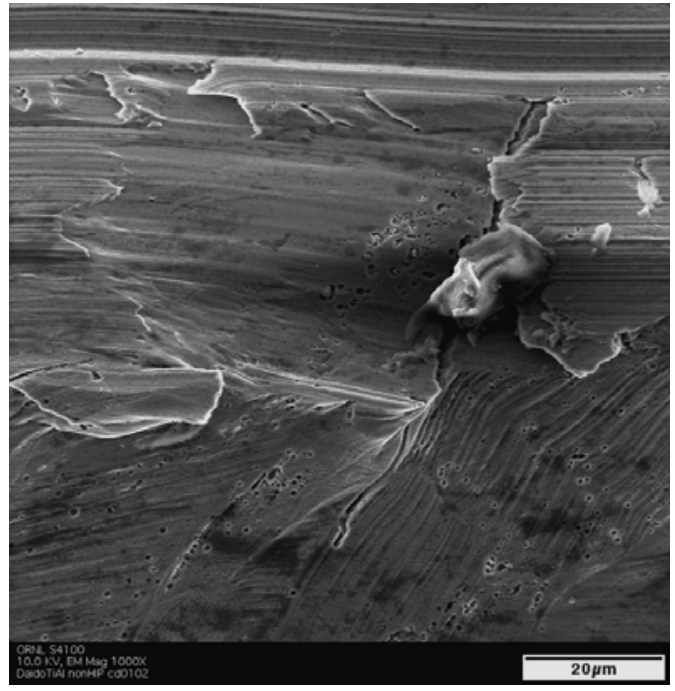

(d)

Fig. 4 SEM micrographs corresponding to a scratch (cd0102, scratch from left to right, chemically etched) in Alloy A showing (a) deformed lamellar layers with inter-lamellar cracking; (b) fractured groove surface with secondary inter-colony cracks; (c) conjugate shear lines ahead of a pile-up; (d) pitting with dense voids along the fracture. 


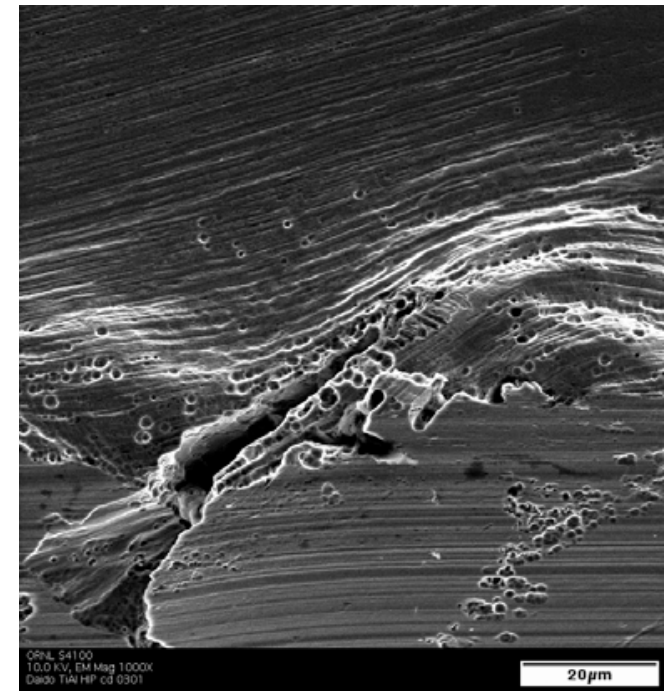

(a)

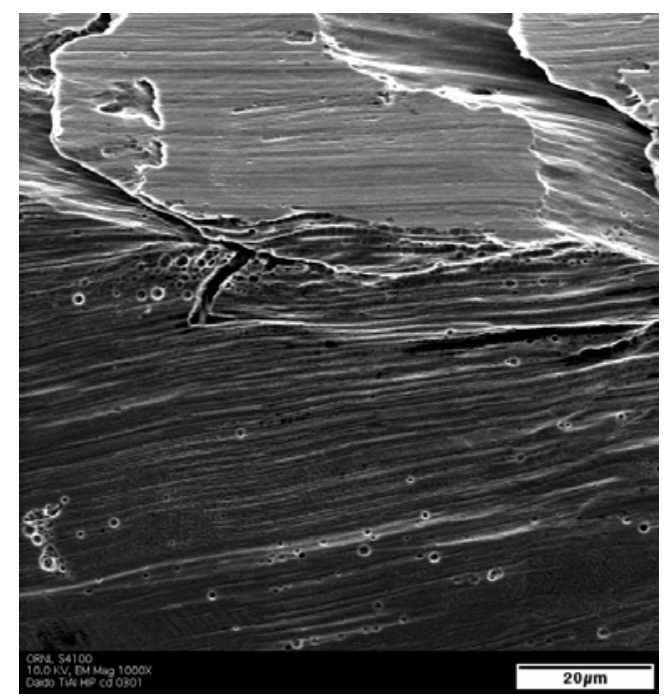

(b)

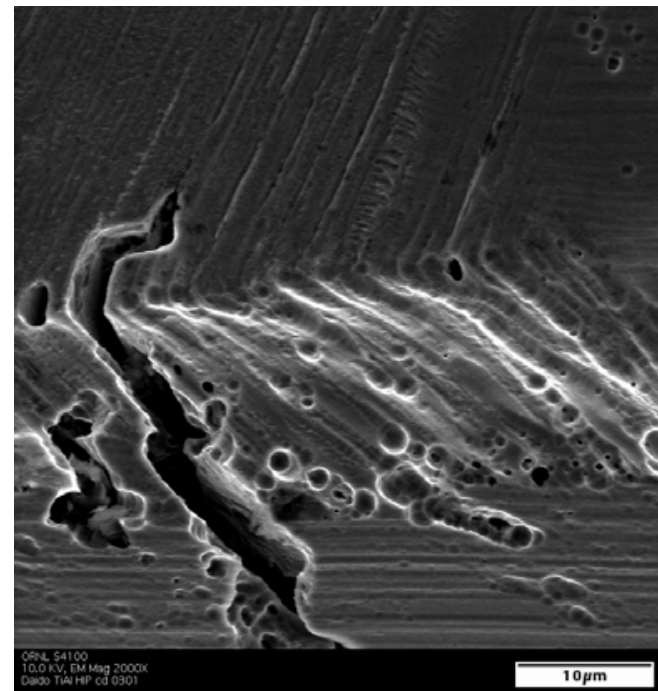

(b)

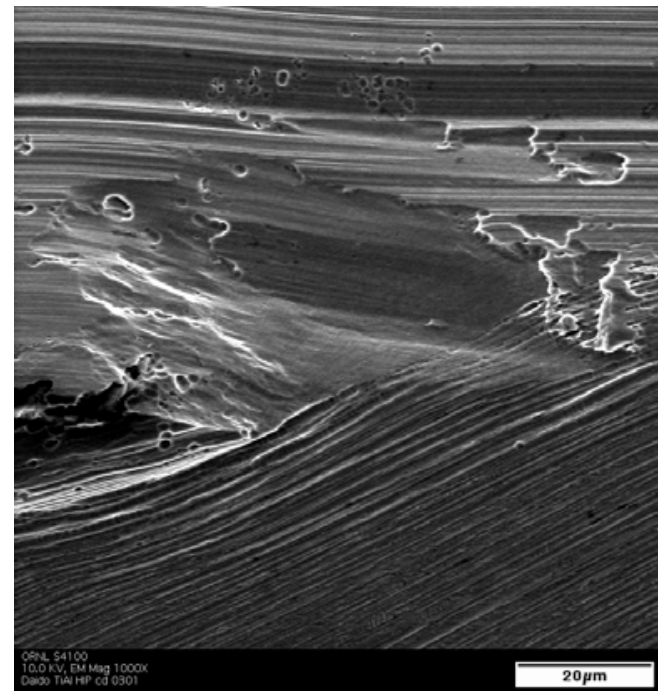

(d)

Fig. 5 SEM micrographs corresponding to a scratch (cd0301, from left to right, chemically etched) in Alloy B showing (a) deformed lamellae with associated crack; (b) deformed lamellae at large angle with associated crack; (c) deep fracture; (d) shallow pitting. 


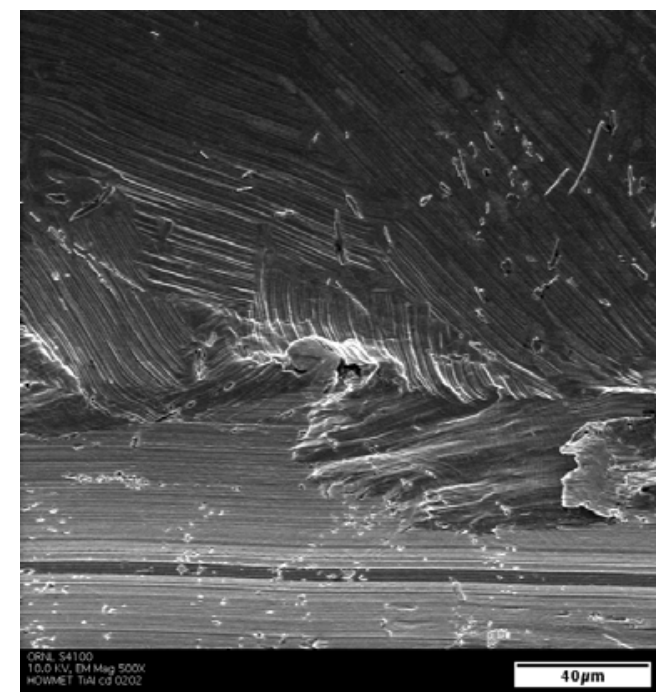

(a)

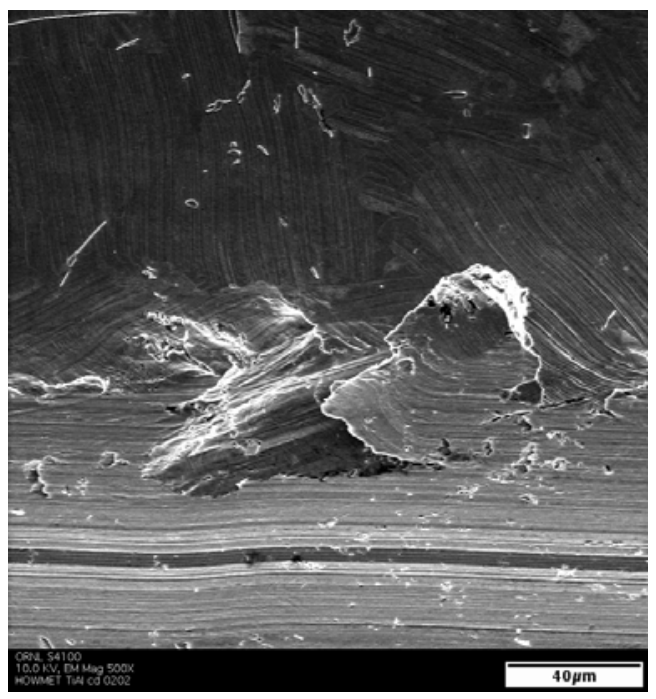

(b)

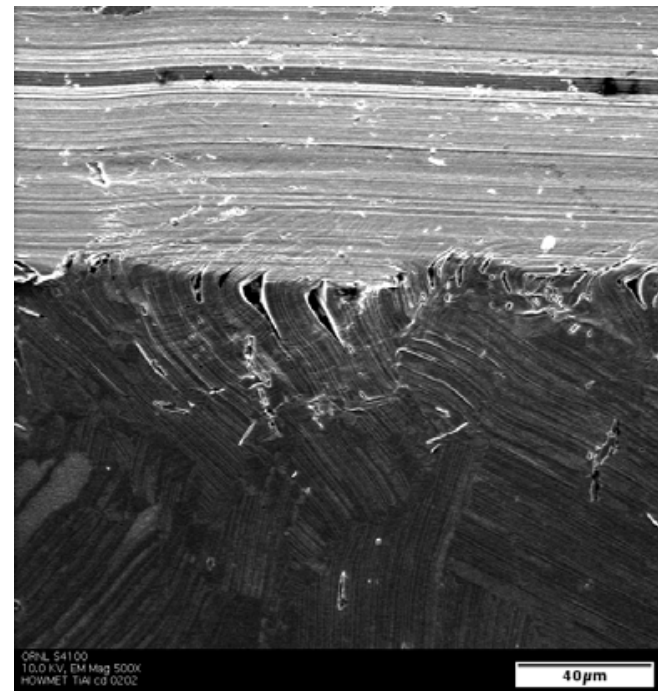

(b)

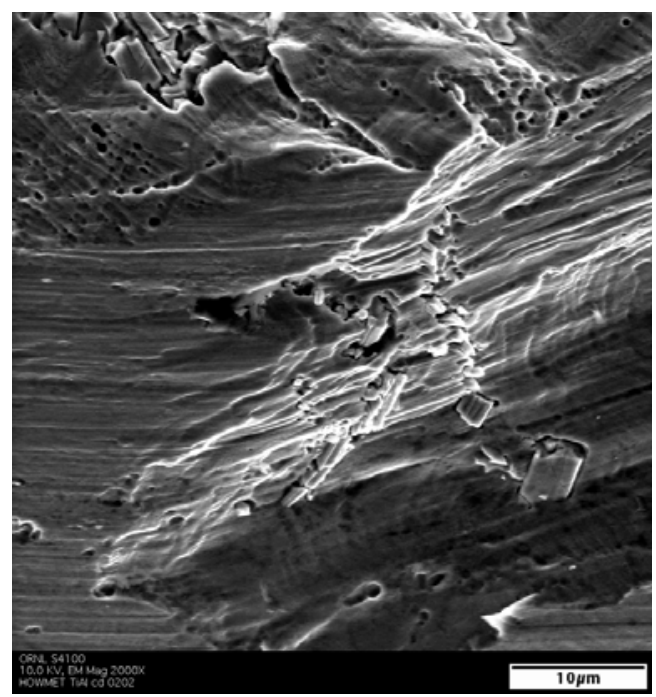

(d)

Fig. 6 SEM micrographs corresponding to a scratch (cd0202, scratch from left to right, chemically etched) in Alloy C showing (a) cleavage on the groove; (b) deformed lamellae with associated inter-lamellar crack; (c) partially detached chipping formed by cleavage; (d) fracture surface as a result of partial detached chipping with dense voids 


\subsection{Scratch Forces}

The time dependent scratch forces captured by load cells were transformed and expressed in terms of the tool position using a linear relationship, in which the tool position in fact corresponds to the aforementioned longitudinal coordinate $\mathrm{x}$ in the 3-D representation of scratch. The force signals of representative scratches for the three TiAl alloys are given in Fig. 7 (a) to (c). The scratch speeds obtained were $\sim 1 \mathrm{~m} / \mathrm{s}$, based on a scratch length of $\sim 3 \mathrm{~mm}$ over a period of $\sim 3 \mathrm{~ms}$. The normal and tangential forces of the three scratches exhibit a bell shape; they rise as the tool tip penetrates into the specimen, reach a peak in the middle, and then fall as the tool returns to the surface. The

force signals are not necessarily symmetrical, especially for the tangential force that is usually skewed toward the right direction (on upright portion of the stroke in the second half of force profile). As a result of that, the curves of OFC (overall frictional coefficient) generally have an ascending trend over the wide middle region of the scratch.

\subsection{Scratch Groove Profiles}

The geometries of the scratch groove section were extracted at every sampling point along the longitudinal axis $\mathrm{x}$, including the depth of groove, groove sectional area, plowing sectional area and removed sectional area (Fig. 8). Among these, the groove sectional area is the sectional area of the scratch below the original level, the plowing sectional area is the sectional area in contact with the tool face during scratch, and the removed sectional area is the removed groove area (i.e. the groove area minus the total area of two side ridges). Some of these quantities were used in the morphological characterization of sliding scratch by various authors [23-26]. 


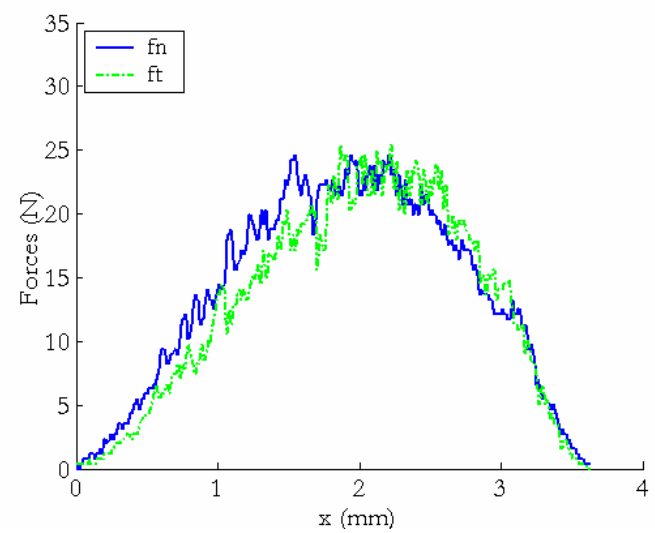

(a)

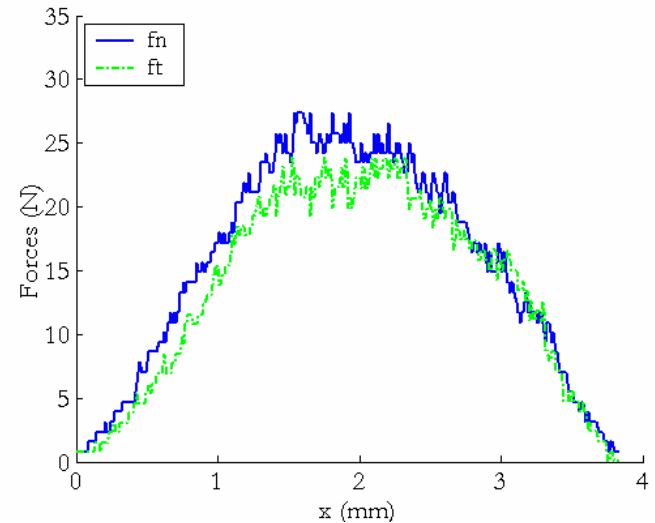

(b)

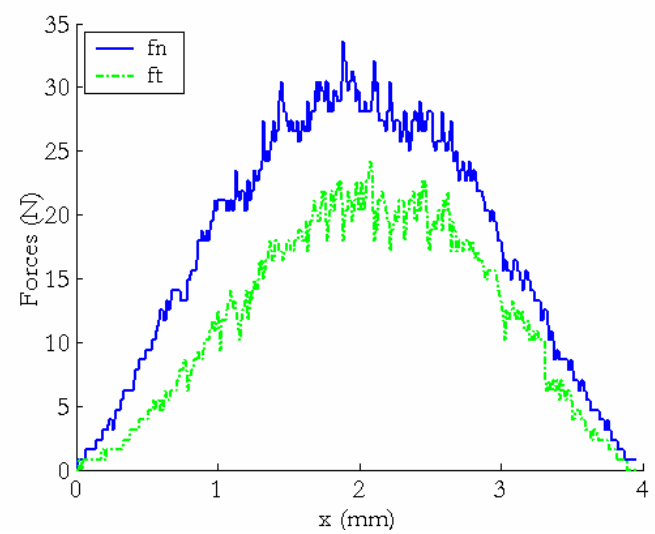

(c)

Fig. 7 Force profiles of typical scratches on (a) Alloy A, (b) Alloy B and (c) Alloy C. 


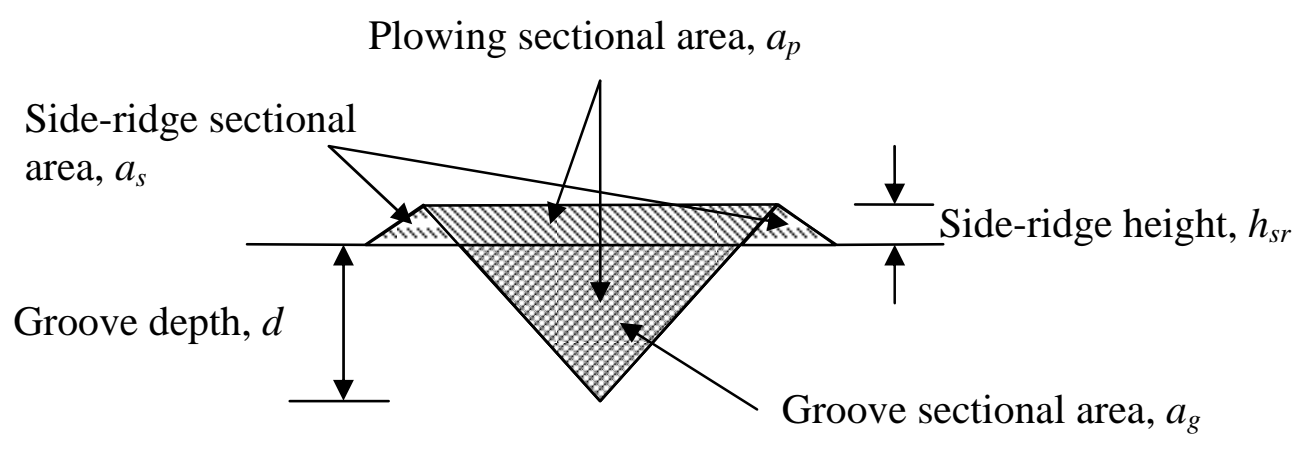

Removed sectional area, $a_{r}=a_{g}-a_{s}$

Fig. 8 Sketch of scratch sectional areas at a given depth of groove; scratch longitudinal axis is perpendicular to the page.

Plotting of these quantities versus the scratch coordinate $x$, therefore, resulted in the derived scratch profiles with regard to groove depth and sectional areas. As expected, the profile of depth of groove shows an arch curve in response to the imposed circular motion of the tool tip. The derived profiles of sectional areas appear with the similar curves, but resemble more the shapes of scratch forces compared to the profiles of groove depth as shown in Fig. 9 where the profiles of depth and sectional areas are presented for the scratches in Fig. 7. These profiles show that the level of the overall groove area is higher than that of the removed area but lower than that of the plowing area. Generally, the profiles of both forces and sectional areas are seen with the oscillations whose amplitude increases proportionally with the depth of penetration. To illustrate the trend, these noise oscillations were removed by a dedicated MATLAB program. The corrected quantities are used in the following analysis. 

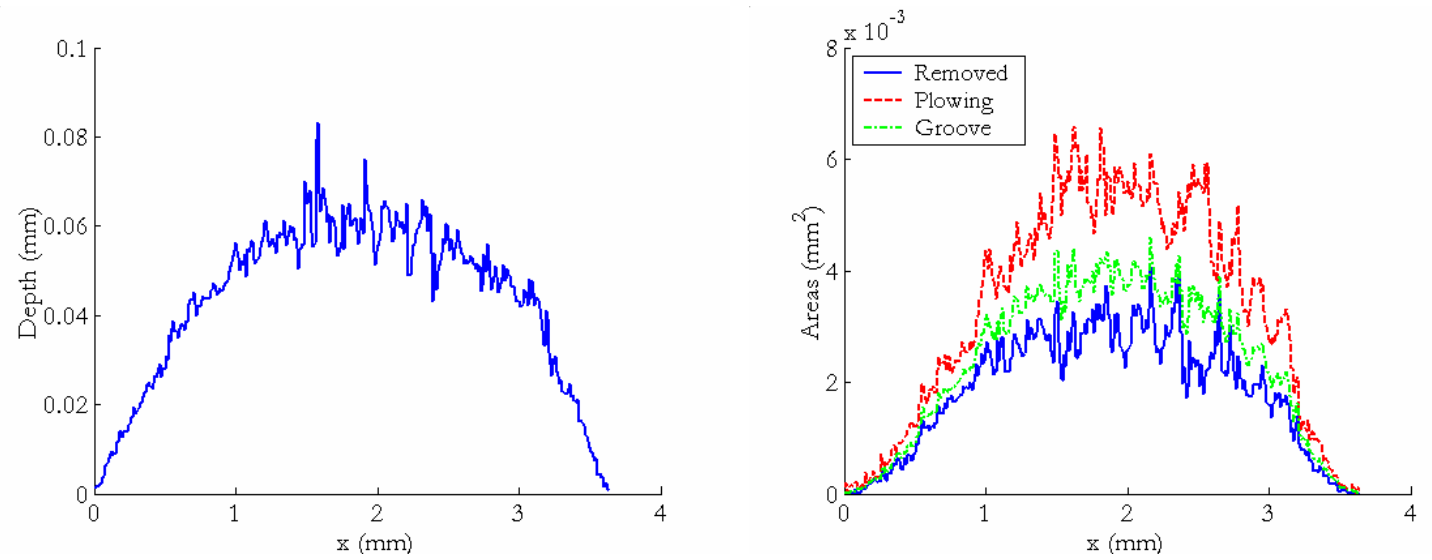

(a)
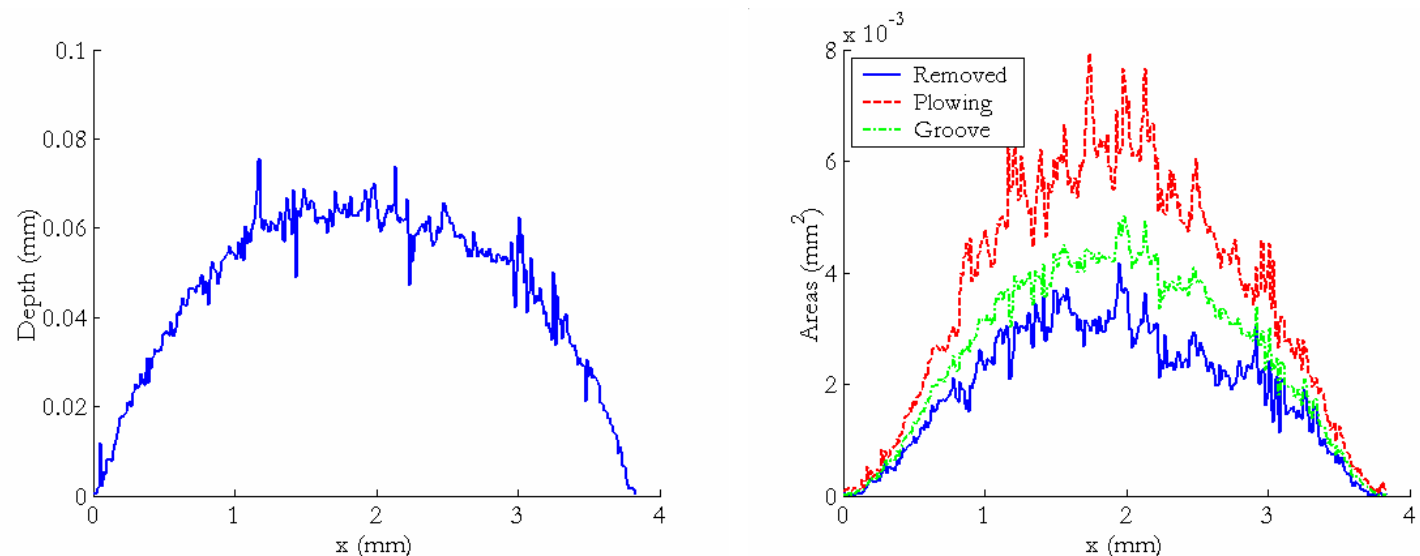

(b)
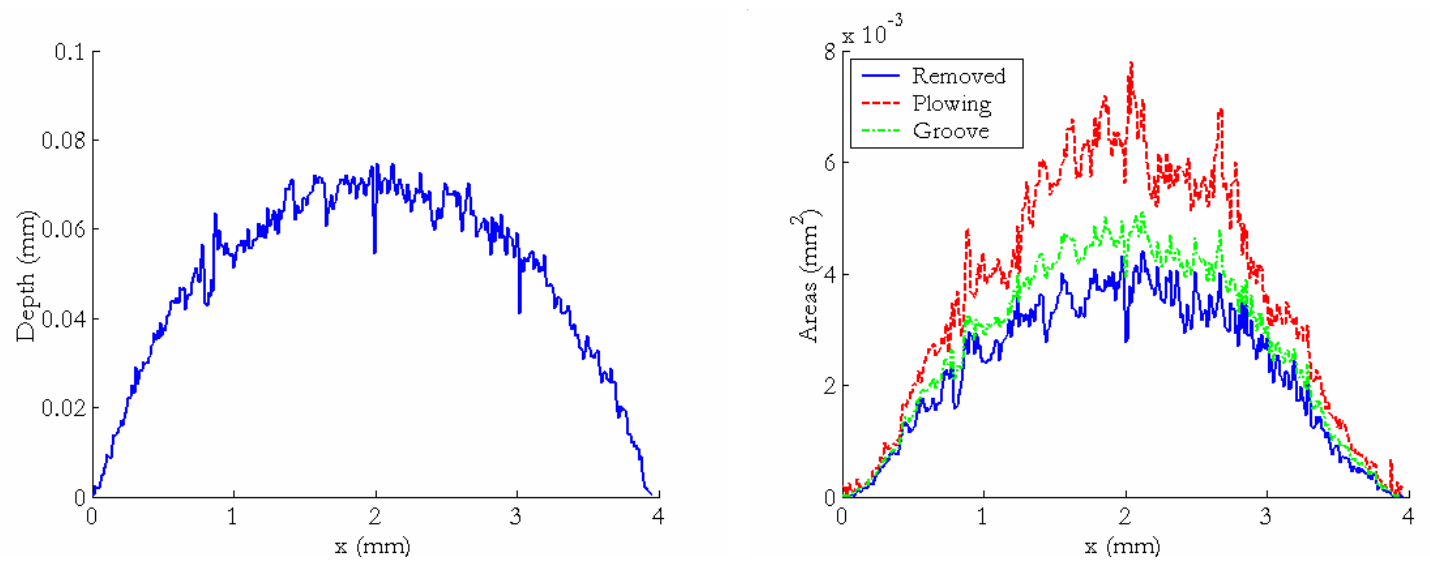

(c)

Fig. 9 Variations of groove depth and sectional areas of typical scratches on (a) Alloy A, (b) Alloy B and (c) Alloy C. 


\subsection{Overall Frictional Coefficient (OFC)}

The variations of OFC (overall frictional coefficient, defined as the ratio of tangential force to normal force) along axis $\mathrm{x}$ are given on the left side of Fig. 10 (a) to (c) for the respective TiAl alloy. The curves of OFC were based on noise-corrected force signals where the trend of these curves is very similar to those in [15, 27]. With a couple of exceptions, the OFCs of the TiAl alloys exhibit an ascending trend over the wide middle region of scratch that can be attributed to the increasing attack angle. The OFCs of Alloy B and C remain close to 1.0 (because of the dominant semi-conic angle of $45^{\circ}$ ) but those of Alloy C apparently fall a little below this level. The OFC curves also show an abrupt fluctuation near the ends of scratch due to the transient property of the process.

\subsection{Degree of Wear}

The differences between the defined sectional areas for a given scratch in Fig. 9 illustrate the susceptibility to material loss or wear. In fact, the degree of wear $[25,26]$ (or the coefficient of material removal [28], defined as the ratio of the removed sectional area to the groove sectional area) of the TiAl alloys also exhibit a certain variation throughout the scratch process as shown on the right side of Fig. 10 (a) to (c). Over the wide middle region of scratch, the profiles of degree of wear generally have a steady decrease with a moderate suppression around the middle, which becomes pronounced in the case of Alloy B. Overall, the degree of wear of Alloy C displays a level slightly higher than the other two TiAls. 

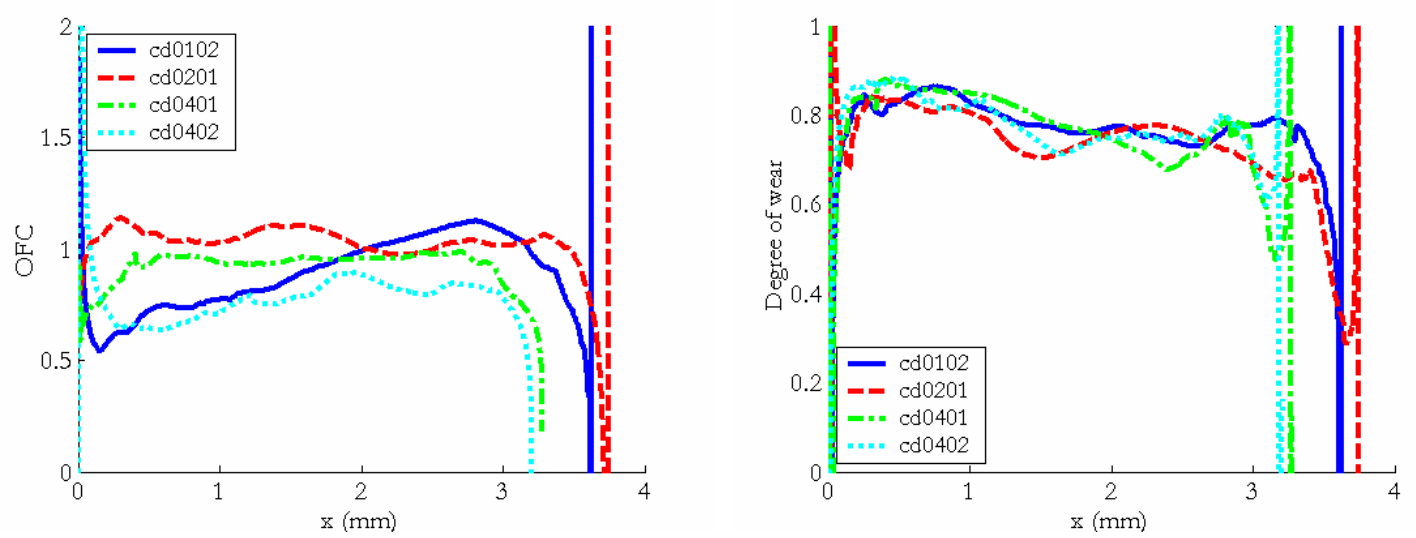

(a)
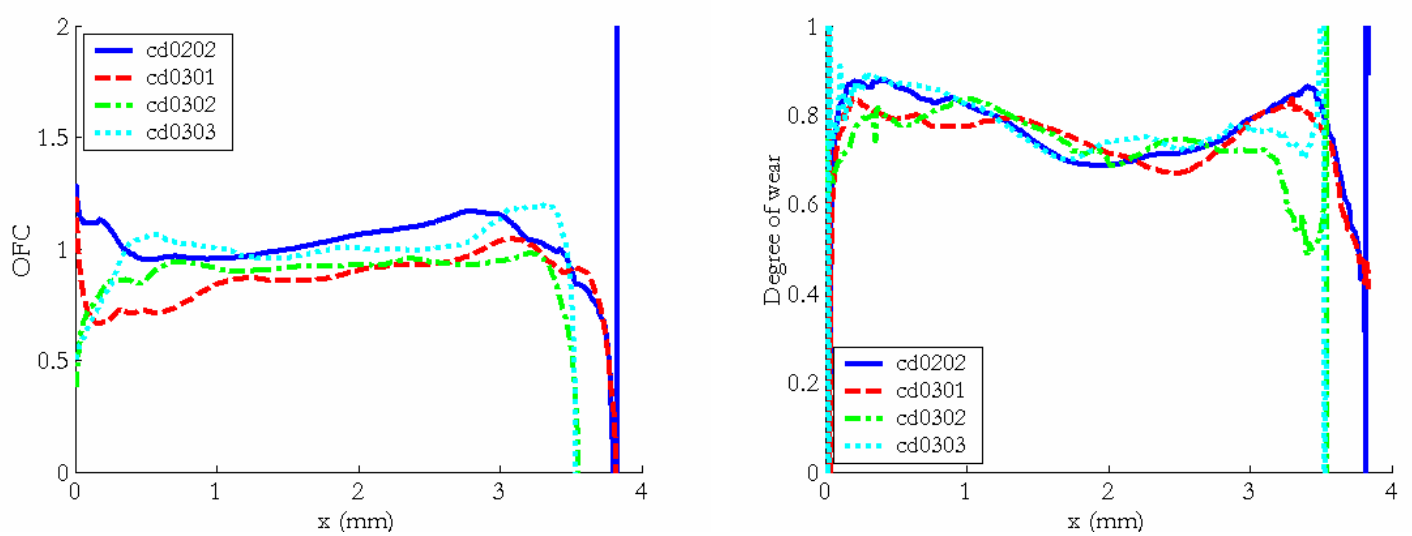

(b)
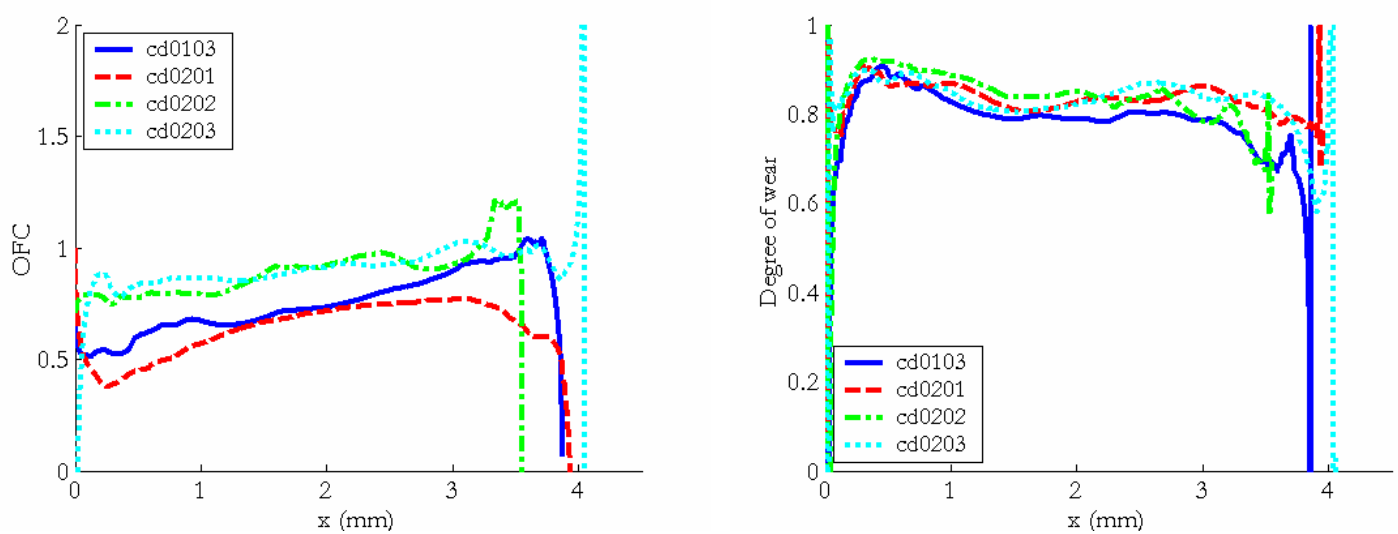

(c)

Fig. 10 Variations of OFC (overall friction coefficient) and degree of wear on (a) Alloy A, (b) Alloy B and (c) Alloy C. 


\subsection{Specific Energy}

Specific energy (defined as the energy dissipation per unit volume of material removal) has frequently been used for the characterization of scratch resistance [29-35]. The availability of the profiles of removed sectional area and tangential force along the scratch axis $\mathrm{x}$ enables a detailed investigation of this quantity. For instance, the specific energy $S_{e}$ at a given $\mathrm{x}$ can be written as following,

$S_{e}=\frac{E}{V}=\frac{\int_{0}^{x} f_{t}\left(x^{\prime}\right) d x^{\prime}}{\int_{0}^{x} a_{r}\left(x^{\prime}\right) d x^{\prime}}$

where $f_{t}$ and $a_{r}$ are the tangential force and removed sectional area, respectively. Accordingly, the specific energy $\mathrm{E}$ can be evaluated as a function of scratch coordinate $\mathrm{x}$ as shown on the left side of Fig. 11 (a) to (c) for the TiAl alloys. It is seen that the specific energy of the TiAls exhibits a series of events: an abrupt rise, a fast drop, and a slow recovery; nevertheless, the specific energy asymptotically approaches a stable level towards the completion of the scratch. This ultimate level defines the traditional specific energy; the quantity introduced in Eq. (1) can also be designated as the progressive specific energy. In particular, the final levels of the progressive specific energy of both Alloy A and Alloy B approach each other towards the end of the scratch, and that of Alloy C falls marginally below those of Alloy B and C.

\subsection{Instantaneous Specific Energy and Scratch Resistance}

Furthermore, the specific energy can also be evaluated over a small incremental of volume removal within an infinitesimal segment of scratch length $\Delta \mathrm{x}$ as shown in the following,

$s_{e}=\frac{\Delta E}{\Delta V}=\frac{E^{\prime} \Delta x}{V^{\prime} \Delta x}=\frac{f_{t}}{a_{r}}$. 
This parameter, called instantaneous specific energy, is more sensitive to the scratch response of materials and can detect the depth dependence of specific energy more effectively. Indeed, as illustrated in the right side of Fig. 11 (a) to (c), the instantaneous specific energy captures the more salient features than the progressive specific energy does. All the features are revealed including the ascending trend as the scratch motion proceeds, the fluctuations near the end of the scratch and even the small maxima near the middle of the scratch (corresponding to the suppression of degree of wear). The instantaneous specific energy is also equivalent to the cutting pressure that is used in the machining community to estimate the cutting force or power in an orthogonal cutting [36].

The scratch resistance $r_{s}$ (defined as the ratio of tangential force to the plowing sectional area) can be evaluated similarly at a given point $\mathrm{x}$,

$$
r_{s}=\frac{f_{t}}{a_{p}}
$$

where $a_{p}$ is the plowing sectional area. From the point of view of tool-specimen interaction, this quantity in fact characterizes the plowing pressure that the tool experiences. It worthwhile to note that some variants of the scratch resistance were previously used in the literature, including plowing hardness [28], tangential dynamic hardness [32], tangential/ dynamic hardness [33] and flow pressure [37]. However, these terms are all based on the same plowing section area that includes not only the part of cross section below the original level but also the part above. The difference between the plowing sectional area and the removed sectional area can be seen in Fig. 8 and the right side of Fig. 9, and the effects on the scratch resistance of the TiAl alloys are shown in the left side of Fig. 12 (a) to (c). Note the plots in Fig. 12 use a different scale from those in Fig. 11; so the scratch resistance is significantly lower than the instantaneous specific energy for these alloys. In most of the cases, the scratch resistance exhibits a steady ascending trend over the middle (particularly for Alloy A and C) and some transients around ends of scratch. 

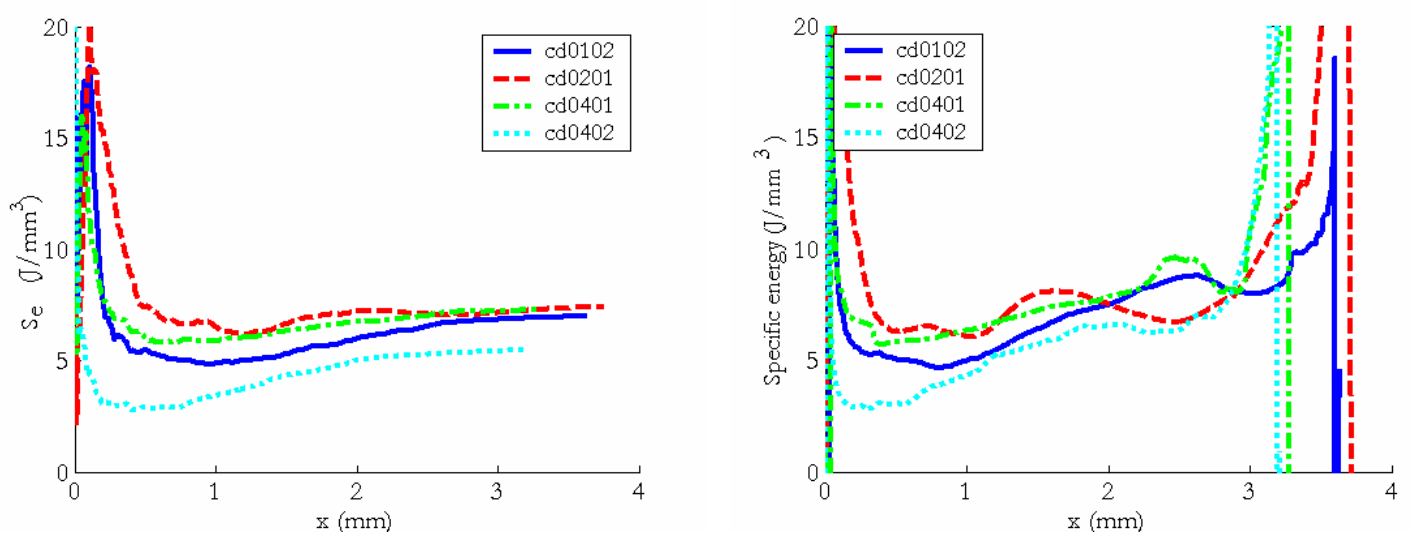

(a)
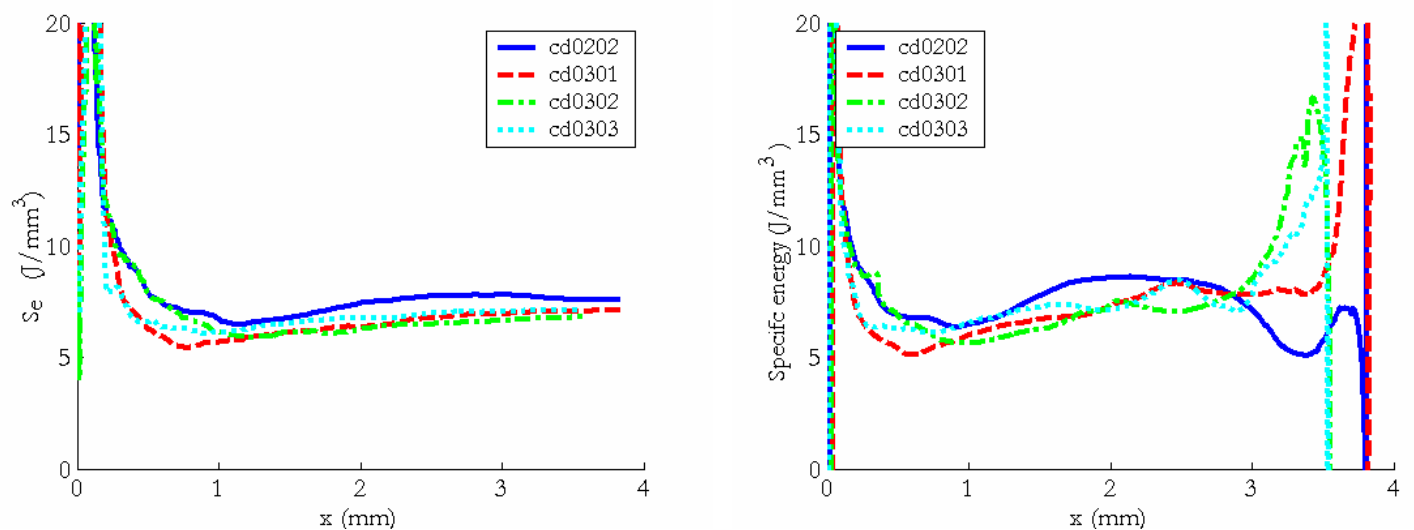

(b)
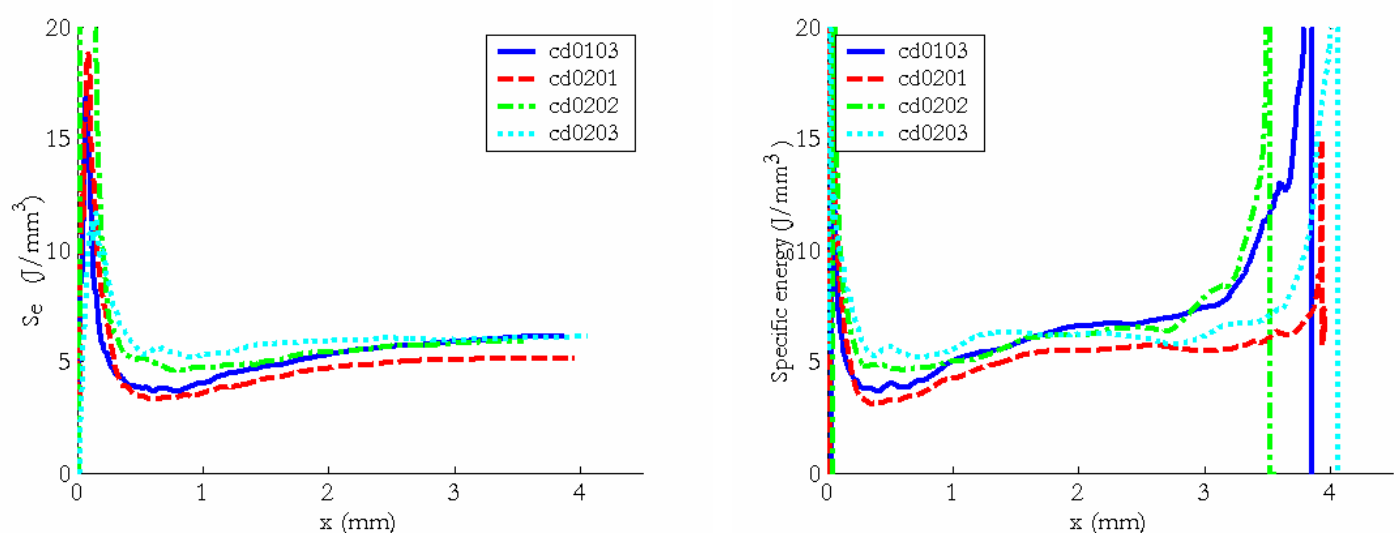

(c)

Fig. 11 Variations of progressive specific energy and instantaneous specific energy on (a) Alloy A, (b) Alloy B and (c) Alloy C. 

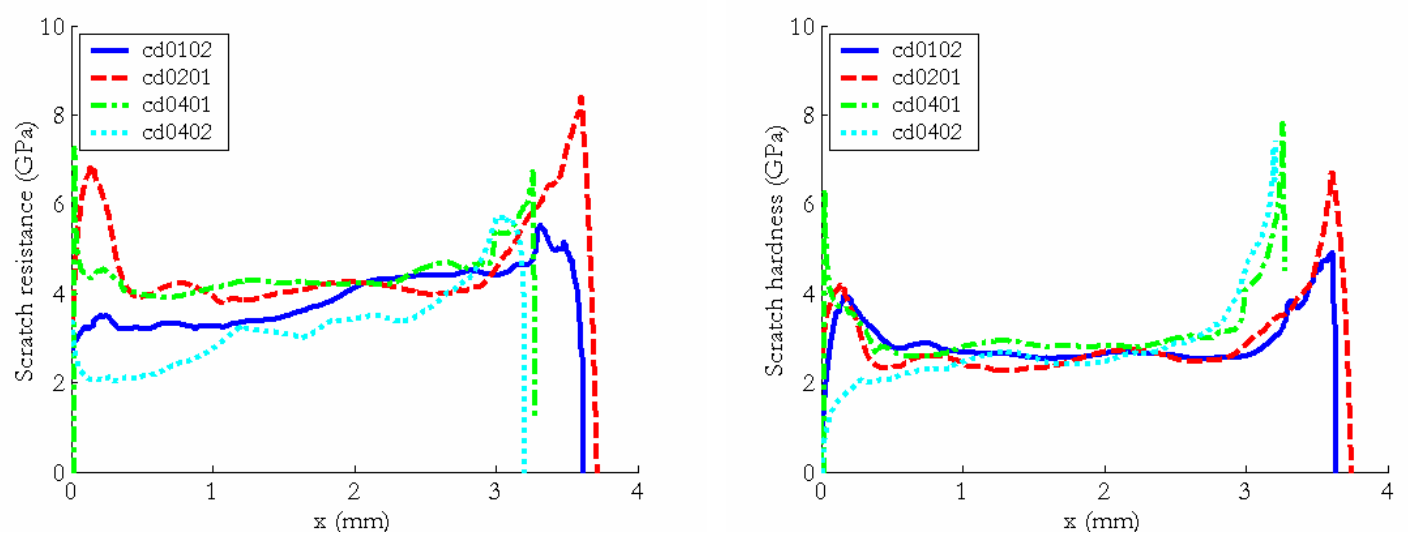

(a)
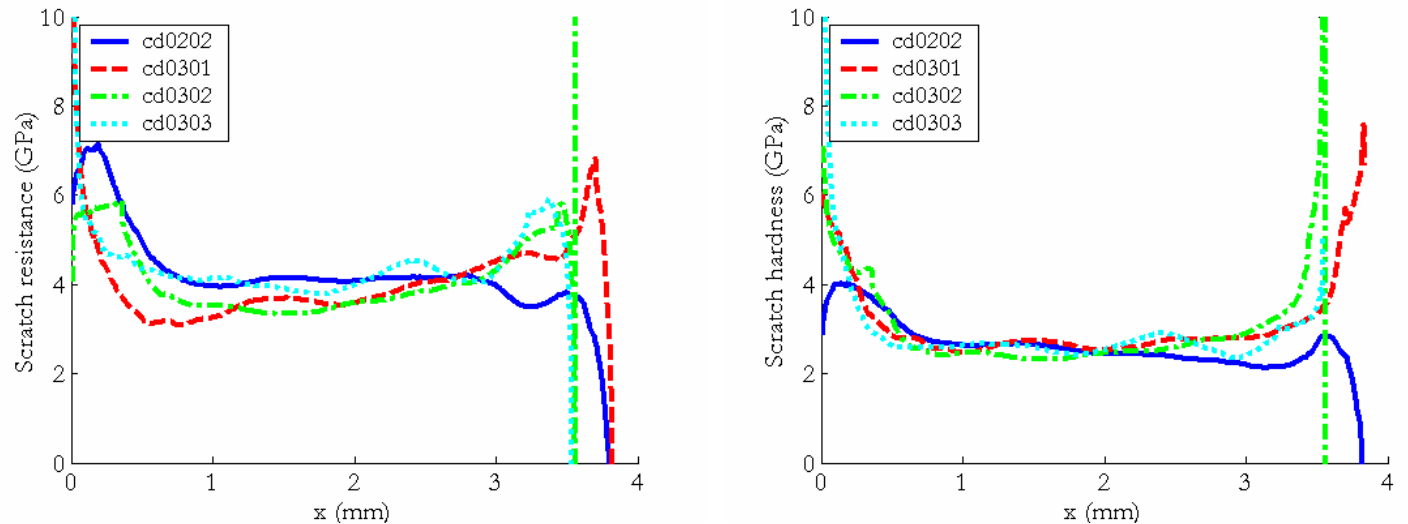

(b)
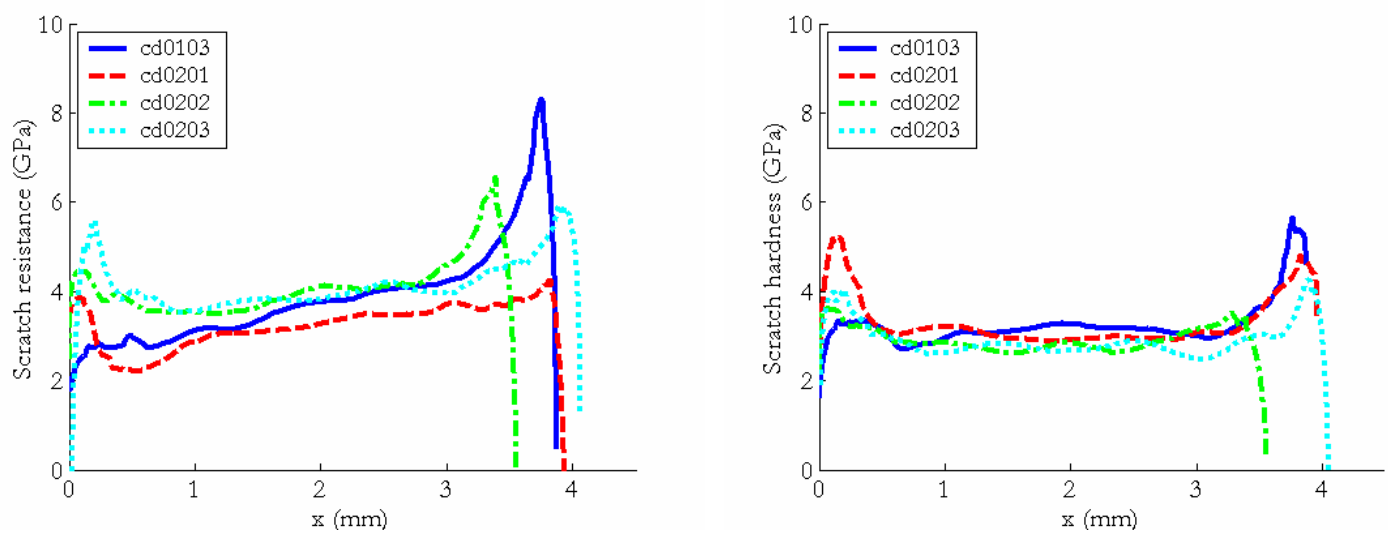

(c)

Fig. 12 Variations of scratch resistance and scratch hardness on (a) Alloy A, (b) Alloy B and (c) Alloy C. 


\subsection{Scratch Hardness}

Scratch hardness (defined as the ratio of the normal force to the projected area of tool-specimen contact on the horizontal plane) [28, 32, 33, 37, 38] cannot be accurately estimated since material was removed as a result of the scratch test and contact is difficult to recover. Some analytical efforts were made before to estimate the contact condition around the tool, but that requires additional inputs [34, 35]. As a result of that, the projected contact area was determined in this study according to the contact geometry and the plowing area as estimated earlier, and scratch hardness $h_{s}$ is thus evaluated as following

$$
h_{s}=\frac{2 f_{n}}{\pi \tan \alpha \cdot a_{p}}
$$

where $f_{n}$ and $\alpha$ are the normal force and semi-conic angle of tool tip. The scratch hardness results are presented on the right side of Fig. 12 (a) to (c). The overall scratch hardness responses are quite similar to those of cutting and plowing pressures. In addition, the scratch hardness exhibits an extended flat over the middle region of the scratch with only one exception showing a slight descending trend in Alloy B. The scratch hardness values of the three TiAl alloys fluctuated about $3.0 \mathrm{GPa}$; a thorough understanding on the differences of the hardness cannot be achieved without further analysis.

\section{ANALYSES}

\subsection{Material Removal Mechanism}

It has been shown that in Fig. 10 that about 70 to $90 \%$ of the sectional area has been removed. As a result of that, the morphological change in the specimen induced by the conical tool was mainly a result of the cutting action. The remaining portion of the groove section of the scratch was either displaced or plowed onto the side ridge and formed the pile-ups. 
Even though extensive pile-ups were developed along the side ridges of scratch in Alloy A and B, no lateral fracture occurred within the shallow subsurface. However, in Alloy C, considerable cleavages took place on the side ridges or the shallow region of groove, resulting in a large increase in the degree of wear or material removal. The increase in wear in the latter case is a consequence of the characteristics of the microstructure of Alloy C; namely, the colony size is comparable to the scratch-induced fracture scale in the transverse direction, which promotes the opportunity for chip formation.

It is interesting to see that the above observation is supported by the independent test on the UTS as shown in Table 2. Under room temperature (RT), Alloy C exhibited an UTS higher than Alloy B due to its finer colony size, although they both exhibit nearly the same level of failure elongation. Below $800^{\circ} \mathrm{C}$, the failure stress and failure elongation of Alloy C were lowered more significantly than those of Alloy B, and that is responsible for the frequent occurrence of cleavages during the scratch test.

The severely bent lamellar layers on the side ridges of the TiAl alloys indicate that the scratched material had experienced tremendous thermal softening due to the plastic deformation. The bending of up to $90^{\circ}$ related to the lamellar layers in Fig. 4 (a), Fig. 5 (b) and Fig. 6 (b) obviously arose from the post-failure stage. For this reason, the calculation of plastic strain based only on the analysis of micrographs may not give a reliable estimate correspondently.

If one focuses on the tool-specimen interaction along the longitudinal axis of the scratch at a given instant, then the system could be modeled as single-point cutting with a large negative rake-angle tool [15, 30,36]. Accordingly, the shear strain $\gamma$ imposed on the primary shear zone can be estimated by

$\gamma=\cot \phi+\tan (\phi+\alpha)$

where $\phi$ is the shear angle with respect to the cutting direction or scratch direction. With a build-up edge (BUE) formed on the tool rake (as evidenced by the welded attachment on the tool tip), the shear angle of cutting is taken as $23^{\circ}$ [15], which results in an imposed shear strain of 5.11 . 
The temperature rise induced by the dynamic deformation is a complex process. In the following, two special situations are considered. First, the deformation is modeled as an adiabatic process in which the temperature rise $\Delta T$ can be calculated by [36, 39]

$$
\Delta T=\frac{\eta \tau \gamma}{\rho c}
$$

where $\eta, \tau, \gamma, \rho$ and $c$ are the conversion coefficients (from plastic deformation energy to thermal energy), shear yield strength, shear strain, density and specific heat, respectively. Among these parameters, the shear yield strength can be estimated according to the Vickers hardness $\left(H_{V}\right)$ - based compressive yield strength $Y$,

$$
\tau=Y / \sqrt{3}
$$

$$
\frac{H_{V}}{Y}=0.5+\frac{2}{3}\left[1+\ln \left(\frac{(E / Y) \tan \beta+4(1-2 v)}{6(1-v)}\right)\right]
$$

where E, $v$ and $\beta$ are the Young's modulus, Poisson's ratio and wedge angle. The relation given by Eq. (8) is a result of the modified Johnson model where the equivalent wedge angle for the Vickers indenter is $19.7^{\circ}[40,41]$. In a typical adiabatic process, $\eta$ could be as high as 1.0 [36]. For a dynamic process such as the pendulum scratch in this study, the deformation of tested TiAls tends to be adiabatic because of their extremely low thermal conductivities (Table 2) and the high speed loading of the tool as well as the confinement of groove wall on the tool-tip. Second, the above-mentioned shear plane can not be fully adiabatic due to the chip flow, and thus the energy is partitioned between the chip and the work piece. The temperature rise after the energy partition can be calculated as following,

$$
\Delta T=\frac{\eta R \tau \gamma}{\rho c}
$$


where $\mathrm{R}$ represents the fraction of total energy leaving the shear zone with the chip and can be estimated by [36]

$$
R=\left(1+1.328 \sqrt{\frac{k \gamma}{v t_{0}}}\right)^{-1}
$$

where $\mathrm{k}, \mathrm{v}$ and $\mathrm{t}_{0}$ are the thermal diffusivity $(k=K / \rho c$ ), cutting speed and un-deformed chip thickness (depth of cut), respectively.

A realistic scratch temperature rise would be located between the estimates of Eq. (9) and Eq. (6). As shown in Table 2, the specific heat and thermal conductivity of the TiAls are temperature dependent to a certain degree. For simplification, the mean value of each property was taken in the analysis. Substituting of the parameters related into Eqs. (9) and (6) yielded $380^{\circ} \mathrm{C}$ and $750^{\circ} \mathrm{C}$ for Alloy A, $433^{\circ} \mathrm{C}$ and $847^{\circ} \mathrm{C}$ for Alloy B and $653^{\circ} \mathrm{C}$ and $1166^{\circ} \mathrm{C}$ for Alloy $\mathrm{C}$ at the maximum depth of groove $(0.070 \mathrm{~mm})$, respectively. The range of predicted values may reflect the spatial variation of the temperature changes within the shearing or influencing zone. Nevertheless, the final temperature in the shear zone would approach the creep temperature limits of the TiAl alloys, and thus the detachment of the chip is facilitated as evidenced by the extensive bent lamellar layers. These observations are in agreement with those made on TiAl machining by Razavi, et al. [42]. It is worthwhile to note that the above analysis has simplified the 3-D scratch process and a realistic simulation certainly calls for the detailed coupling analysis of thermal softening and material removal.

\subsection{Specific Energy, Scratch Resistance and Scratch Hardness as a Function of Groove Depth}

As shown before, the OFC increases over the middle region of the scratch due to the increasing attack angle (formed between the tool surface and the flat surface of specimen). The varying attack angle during the scratch motion influences the cutting pressure, the plowing pressure and scratch hardness in special manners [15, 33, 37, 4345]. In the single-grit pendulum scratch, the process becomes more involved because both the attack angle and the depth of groove change continuously. A simplified 
decoupling procedure is used to eliminate the effect of the attack angle [17], although a detailed analysis could more appropriately account for the evolution of contact [34, 35].

The elimination of the attack angle effect enables us to examine more clearly the specific energy as related to the groove depth that has been extensively pursued in the literature [36, 46-49]. With the groove depth and pressure profiles available, the relation between the cutting pressure and groove depth can be readily resolved with the abovementioned decoupling procedure [17]. The representative results for the TiAl alloys are presented in Fig. 13 (a) to (c). It should be noted that the determination of cutting pressure in the depth region below $\sim 0.004 \mathrm{~mm}$ became quite elusive due to the noisecorrection procedure used. The variation of specific energy actually displays clearly an appreciable trend except for that of the scratch cd0201 in Alloy A. As shown in Fig. 13, the specific energy of the TiAl alloys drops abruptly at depth around $0.01 \mathrm{~mm}$ and then approaches into a relatively steady state, and that is followed by a slight recovery (curveup) beginning at a depth of $\sim 0.04 \mathrm{~mm}$. The recovery seems particularly evident in the case of Alloy B. Overall, the steady level of cutting pressure in Alloy C is relatively lower than those of Alloy A and B.

The variations of scratch resistance and scratch hardness along the groove depth can be obtained by using the same procedure, and the representative results are presented in Fig. 14 (a) to (c) as well. The initial positive slope of the scratch resistance in the range of $<0.004 \mathrm{~mm}$ again results from the noise-correction procedure. Generally, the scratch resistance and the scratch hardness of all the tested TiAls are quite stable after a slight decline. 


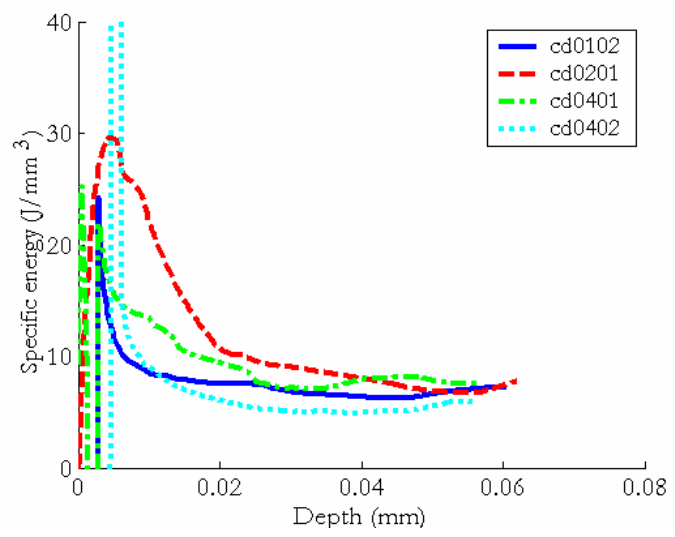

(a)

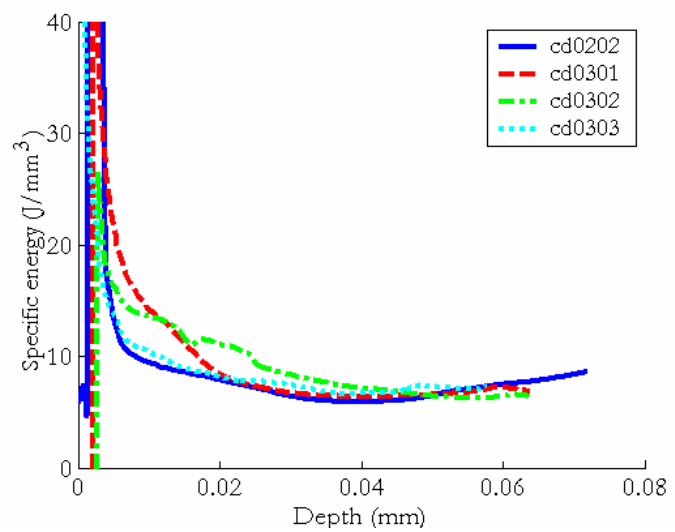

(b)

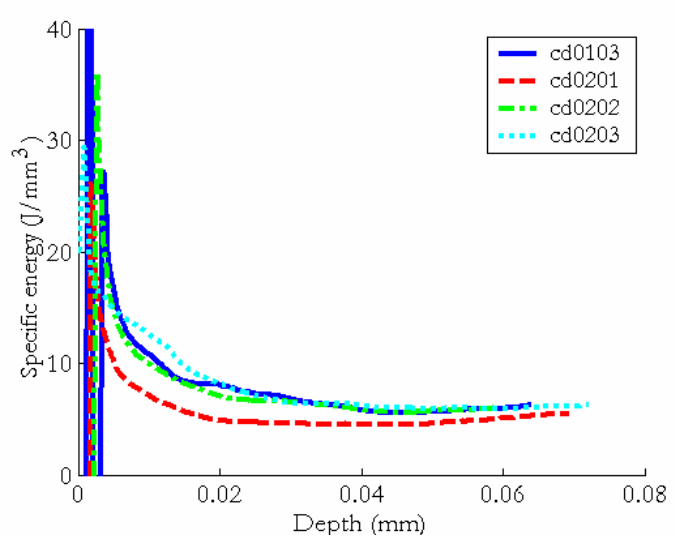

(c)

Fig. 13 Specific energy as a function of groove depth for (a) Alloy A, (b) Alloy B, and (c) Alloy C. 

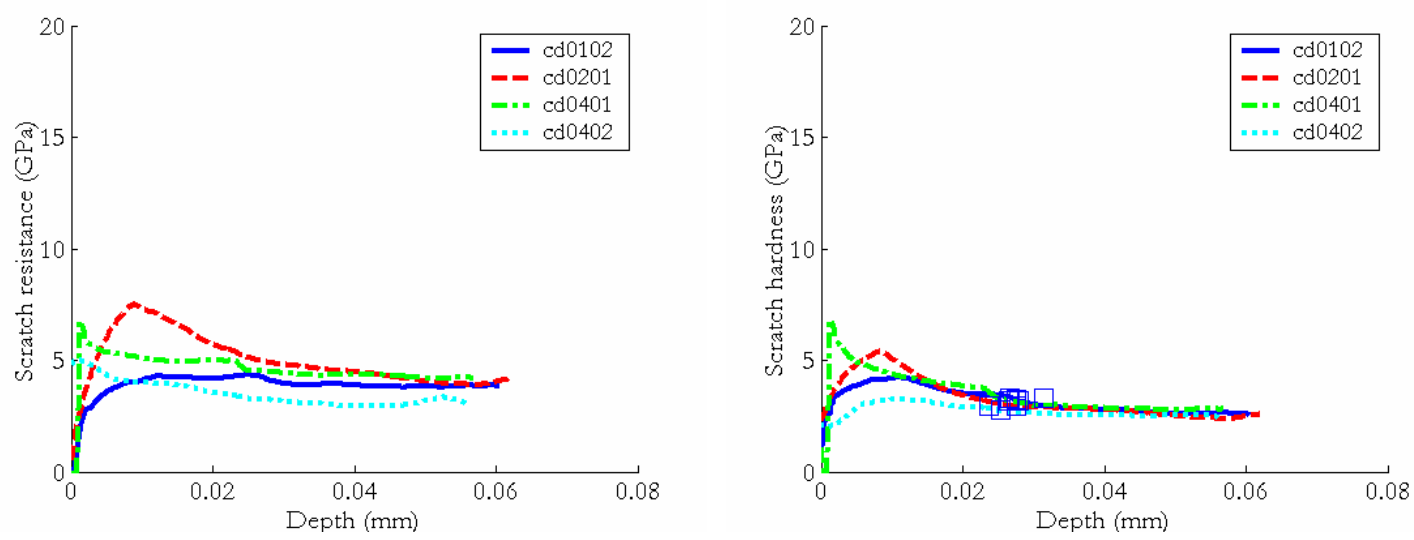

(a)
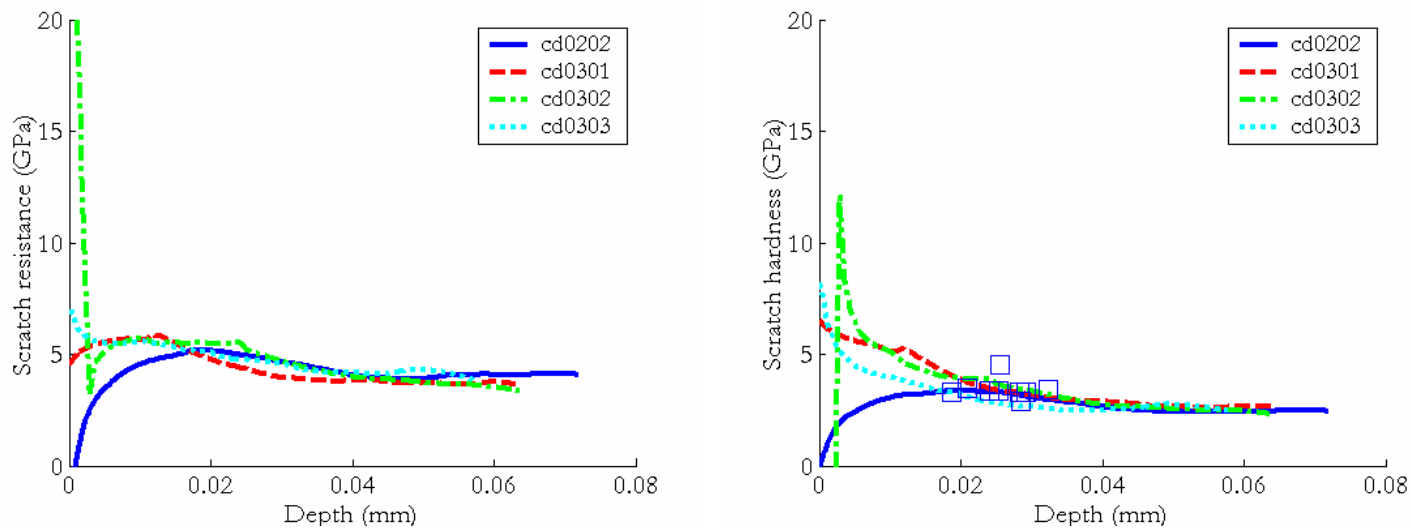

(b)
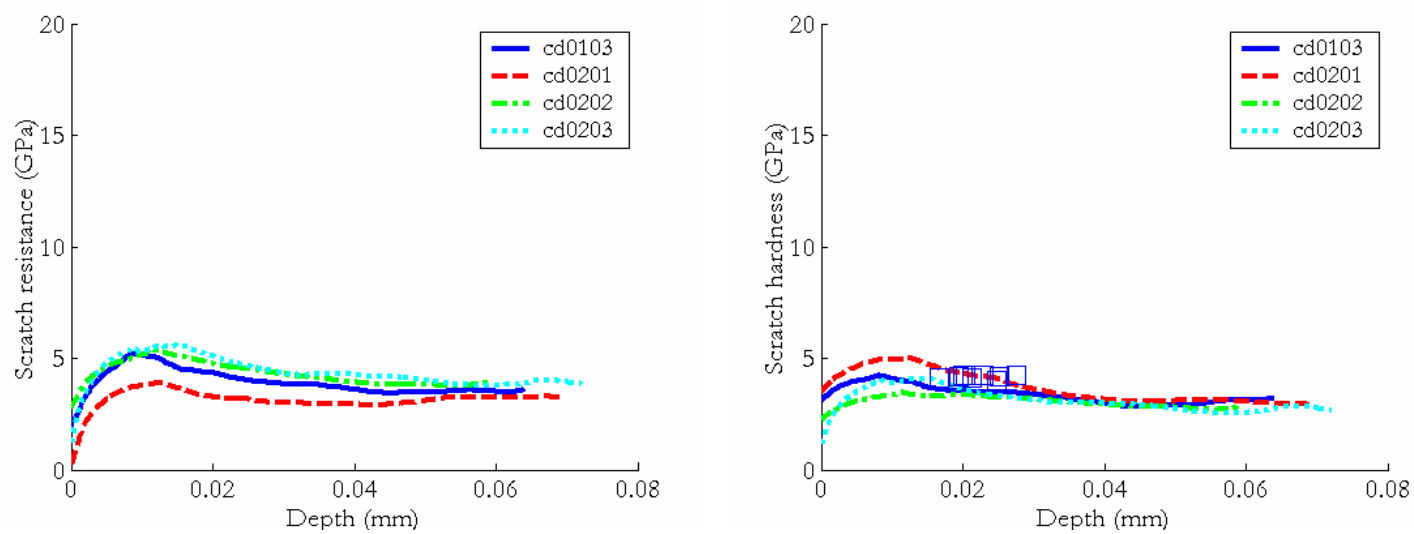

(c)

Fig. 14 Scratch resistance and scratch hardness as a function of groove depth for (a) Alloy A, (b) Alloy B, and (c) Alloy C. 
The specific energy, scratch resistance and scratch hardness were then averaged for each TiAl alloy and the results are presented in Fig. 15 (a) to (c). The averaging was performed for each alloy in order to reduce the uncertainty introduced by the heterogeneities of materials sampled by each scratch. Among the selected scratches, scratch cd0201 in Alloy A behaved abnormally in comparison with other members of the same alloy, especially around the depths of $0.010-0.020 \mathrm{~mm}$ where the cutting pressure looks extremely high, and therefore it was excluded from the analysis in Fig. 15.

Additional quantities are also presented in the plots of Fig. 15 to show the possible implications including the grooving pressure $p_{g}$, depth-based grooving pressure $p_{d}$ and depth-based scratch hardness $h_{d}$ as defined by

$$
p_{g}=\frac{f_{t}}{a_{g}}
$$

$p_{d}=\frac{f_{t}}{\tan \alpha \cdot d^{2}}$

$h_{d}=\frac{2 f_{n}}{\pi \tan ^{2} \alpha \cdot d^{2}}$

where $a_{g}$ and $d$ are the groove section area and groove depth as shown in Fig. 8.

The observations with regard to the analysis related to the TiAl alloys can be summarized as following.

1) These quantities exhibit various sensitivities to the groove depth, among which, the depth-based grooving pressure and depth-based hardness show the most significant sensitivity in the low end of groove depth and the specific energy displays the moderate sensitivity. Beyond a certain depth, all the quantities run into a relatively steady stage thereafter the variation becomes slow with the increasing depth of groove.

2) The specific energy and scratch hardness form the upper and lower bounds of variation in the steady stage and the distance of the bounds of Alloy B appears to be larger than those of other two TiAls. The level of grooving pressure is generally lower 
that of the specific energy, but higher than that of scratch resistance. These observations correspond to the measurements on respective sectional areas.

3) The curve of the specific energy in the later steady stage apparently defines a characteristic depth of groove at which the specific energy behaves differently; namely, recovered from a relatively steady state. The characteristic depth may signify the dominant role of thermal softening during the scratch that promotes the formation of pileups when TiAl becomes more ductile [42]. The pile-ups lower the removed sectional area and, in turn, raise the instantaneous specific energy or cutting pressure.

4) The difference between depth-based grooving pressure and measured grooving pressure in the low range of depth is attributed to the underestimation of groove sectional area. The underestimation occurred because of elastic recovery in the corresponding range of the groove depth. The observed difference diminishes with the increasing depth of groove since the role of cutting in determining the sectional area apparently outweighs that of elastic recovery in the given depth of groove.

5) The depth-based scratch hardness is found to approach and fall below the measured scratch resistance with the increasing depth of groove in each of TiAl alloys; and the intersection of the curves is different for each alloy. This observation is not a coincidence because these two quantities are defined in terms of normal and tangential forces, respectively. For a $45^{\circ}$ semi-conical tool, the depth-based contact area projected onto the horizontal plane is 1.57 times of that projected onto the vertical plane. Numerically, the excessive contact area (on the horizontal plane) is equivalent to the projection of sectional area produced by the formation of side ridge. The above observation shows that the contact around the tool in the scratch approaches more the hydrostatic state in the large depth of groove given that the OFC is around 1.0 in the corresponding range. 


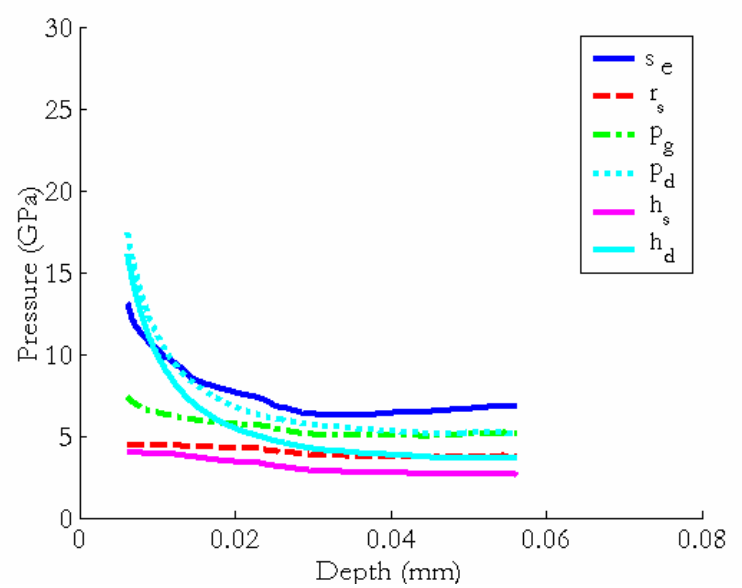

(a)

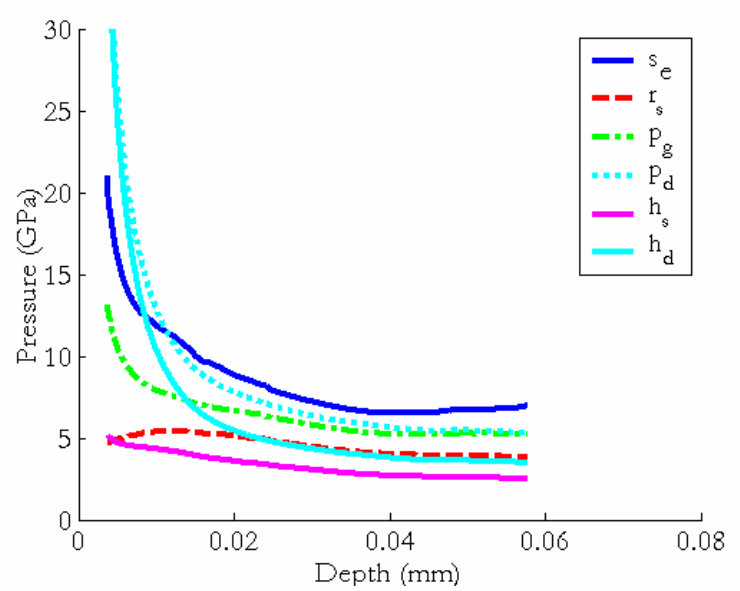

(b)

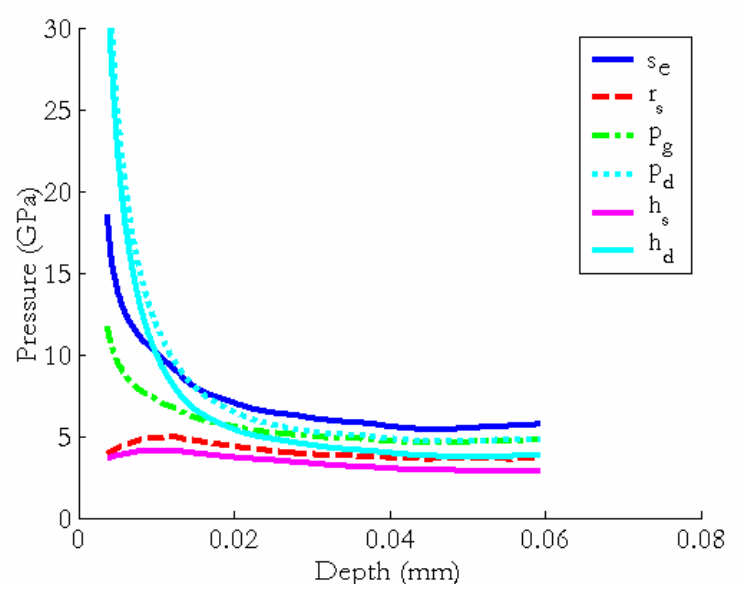

(c)

Fig. 15 Averaged pressures as a function of groove depth for (a) Alloy A, (b) Alloy B and (c) Alloy C. 


\subsection{Scratch Hardness as Related to Indentation Hardness}

It is desirable to attempt to correlate the data from the scratch testing with those from indentation testing [31-33, 37]. For this reason, dynamic indentation tests were conducted on the same TiAl alloys using a novel dynamic hardness tester [19-21]. The dynamic indentation was employed here because the loading rate is within the same rate regime as that of dynamic scratch mentioned in section 2. A Vickers indenter was employed in the tests and the yield strengths of material were deduced according to the modified Johnson model as shown in Eq. (8) [40, 41]. The estimated yield strengths were subsequently used in calculations of dynamic conical hardness by considering that the penetration of conic indenter was same as that of Vickers indenter (1/7 of Vickers diagonals). The indentation hardness values obtained for the alloys are plotted as unfilled boxes on the right side of Fig. 14 (a) to (c). The results show that the indentation hardness values are equivalent to the scratch hardness within the corresponding depth range, which further verifies the effectiveness and efficiency of current approach. By using a number of single-grit pendulum scratches, the specific energy and the hardness as well as their variation related to the groove depth can be examined readily.

\subsection{Two-parameter Model Analysis on Cutting Pressure and Scratch Hardness}

The observations in Fig. 15 reveal that the specific energy and scratch hardness define the upper and lower bounds of the quantities over the studied range of depth. Therefore, here we focus on the specific energy $s_{e}$ and scratch hardness $r_{s}$.

The variation of specific energy or cutting pressure with the depth of groove measures the size effect of specific energy as discussed in studies of material removal [46-48]. Hypothetically, the total specific energy in the process of material removal can be decomposed into three subcomponents that are respectively related to cutting (chip formation), plowing and friction. It is the contributions of plowing and friction that leads to the fluctuation of specific energy in the low depth range, and that of cutting that provides a base line of specific energy. The analysis in section 4.2 revealed that the scratch resistance or plowing pressure indeed shows a depth-related variation, but is not as noticeable as the specific energy. It seems that both friction and modification of contact such as BUE play substantial roles in the abrupt rise in the low depth range. 
Nevertheless, a comprehensive size effect can be modeled by using a linear relation between the specific energy and the inverse of depth of groove as suggested by Hwang, Evans and Malkin $[46,48]$ that is called as HEM model thereafter.

The linear function of the inverse of depth of penetration holds also for the indentation hardness, and has been found to be obeyed by both ductile [50-53] and brittle materials [54-57], even though the underlining physical mechanisms may be different. For instance, in the proportional specimen resistance (PSR) model, the indentation load is considered to be supported by the indent pressure and the proportional specimen resistance (i.e., the specimen resistance is directly proportional to the indent size), which results in a two-parameter quadratic form of indent size or depth [54, 55]. The linear relation between the indentation hardness and the inverse of size can thus be derived. Although it is phenomenologically based, the PSR concept provides a solution to the dilemma related to the unacceptable surface energy value and is proved to be applicable to a variety of materials. With regards to the above, the linear relation between the indentation hardness and the inverse of depth was also equivalently employed in the analysis of scratch hardness.

The HEM model and the PSR model can be transformed and rewritten in the following forms, respectively

$s_{e} \cdot d=b_{1}+b_{2} d$

$h_{s} \cdot d=a_{1}+a_{2} d$

where $b_{1}, b_{2}, a_{1}, a_{2}$ are the parameters depending on curve-fitting [48, 54-56]. Since either of the HEM model and the PSR model uses only two parameters, we simply refer to each as a two-parameter model. The analysis results on the TiAl alloys as applied to the specific energy and the scratch hardness are given in Fig. 16 (a) to (c). 

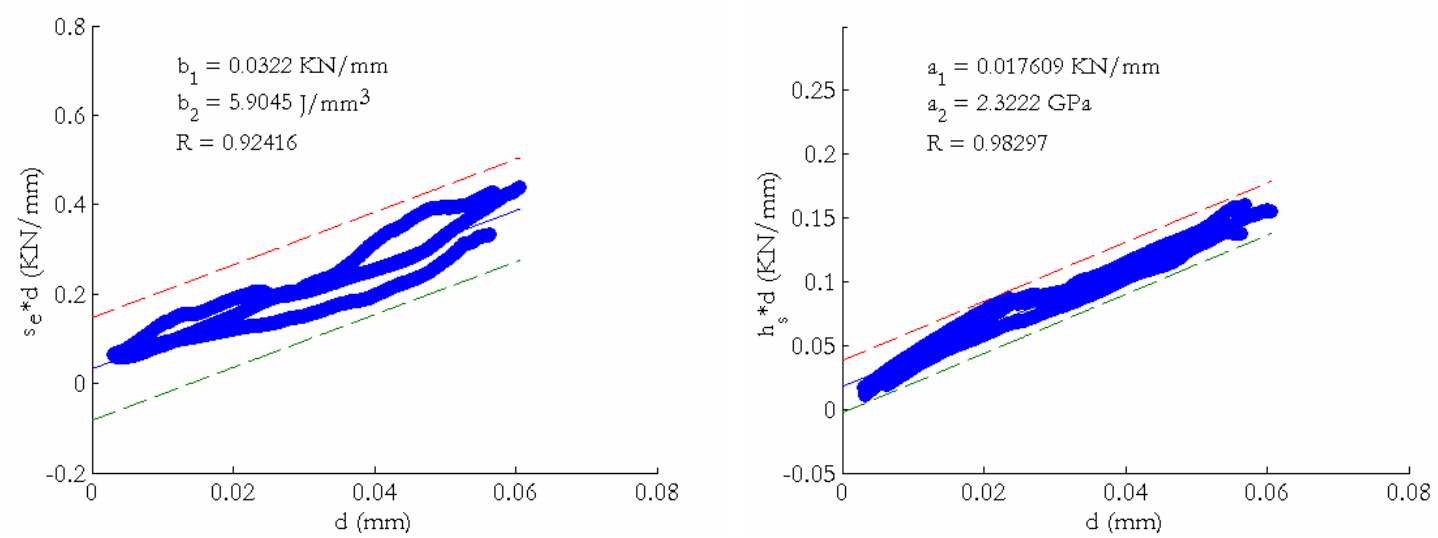

(a)
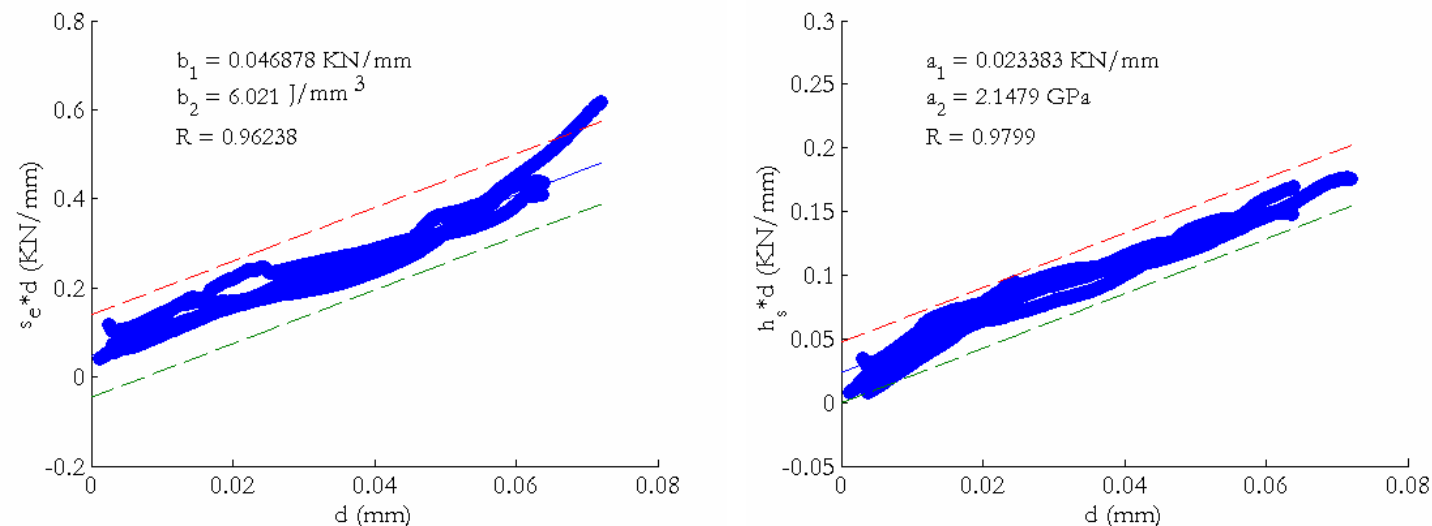

(b)
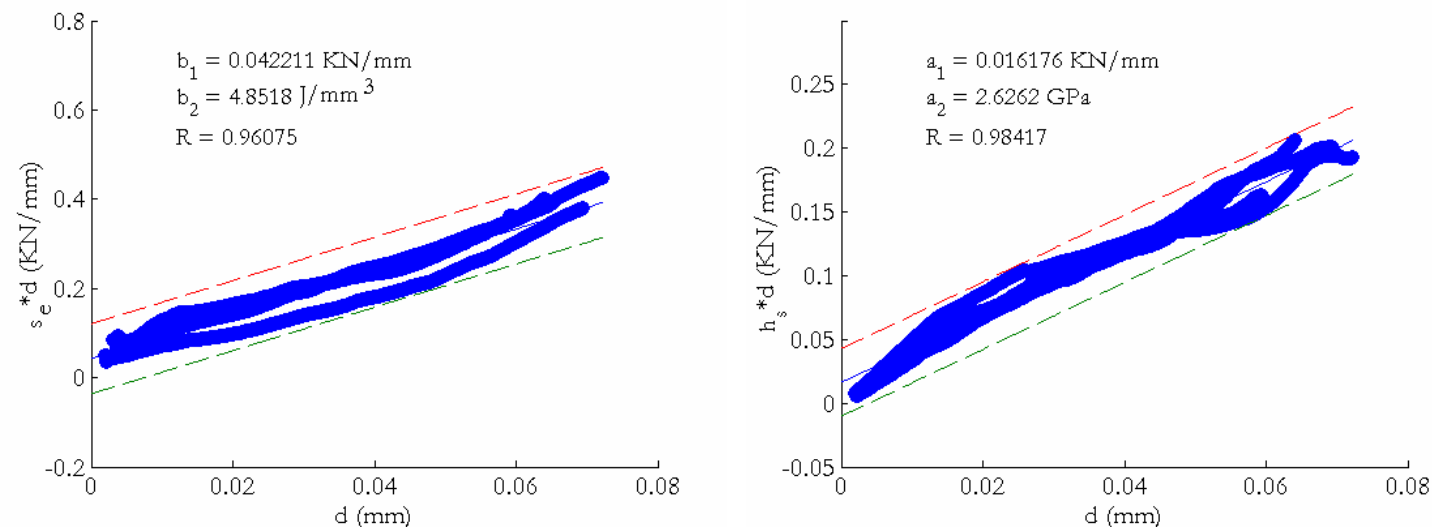

(c)

Fig. 16 Analysis of specific energy and scratch hardness as a function of groove depth for (a) Alloy A, (b) Alloy B, and (c) Alloy C. 
The parameters obtained by the procedure are illustrated in Fig. 16 and listed in Table 3 as well. The depth-independent specific energy $b_{2}$ of Alloy C (4.852 GPa) is lower than those of Alloy A and B (5.905 and 6.003 GPa, respectively), while the coefficient $b_{1}$ of Alloy B $(0.048 \mathrm{KN} / \mathrm{mm})$ appears to be higher than those of other two. On the other hand, the depth-independent scratch hardness $a_{2}$ of Alloy C (2.626 GPa) is higher than those of Alloy A and B (2.322 and 2.148 GPa, respectively), and the coefficient $a_{1}$ of Alloy B $(0.023 \mathrm{KN} / \mathrm{mm})$ is again higher than those of other two.

\begin{tabular}{l|l|l|l|l}
\hline Materials & $\begin{array}{l}\mathbf{a}_{1} \\
(\mathbf{K N} / \mathbf{m m})\end{array}$ & $\begin{array}{l}\mathbf{a}_{2} \\
(\mathbf{G P a})\end{array}$ & $\begin{array}{l}\mathbf{b}_{\mathbf{1}} \\
(\mathbf{K N} / \mathbf{m m})\end{array}$ & $\begin{array}{l}\mathbf{b}_{2} \\
\left(\mathbf{J} / \mathbf{m m}^{3}\right)\end{array}$ \\
\hline Alloy A & 0.017 & 2.322 & 0.032 & 5.905 \\
\hline Alloy B & 0.023 & 2.148 & 0.047 & 6.021 \\
\hline Alloy C & 0.016 & 2.626 & 0.042 & 4.852 \\
\hline
\end{tabular}

Table 3 Two-parameter model analysis of the tested gamma titanium aluminides

Given a full lamellar structure, the yield strength generally follows the Hall-Petch function of grain or colony size [58]. In this regard, Alloy C has a propensity to have higher yield strength and higher hardness than Alloy A and B since Alloy C has a smaller colony size. The observations concerning the scratch hardness apparently is consistent with the Hall-Petch relation.

The results from nanoindentation tests showed that, for a given TiAl, the hardness exhibited a certain degree of variation when the indenter samples different lamellae [12]. The alpha phase lamellae displayed higher hardness than the gamma phase but the difference was not very significant. The spacing, orientation and phase of lamellae generally contribute to the local variation [3] that is obviously seen in the oscillation of scratch forces. Nevertheless, the highest depth-independent specific energy certainly signifies that Alloy B has the highest capability of energy dissipation during the dynamic scratch even though its hardness is lower than the other two. 
In addition, the plots on the left of Fig. 16 (a) to (c) also illustrate a transition depth where the slope of the lines becomes higher. The transition depth takes place around $0.040 \mathrm{~mm}$, corresponding to the characteristic depth of specific energy in Figs. 13 and 15. The transition shall indicate the critical point when the thermal softening becomes particularly significant as mentioned above.

\section{CONCLUSIONS}

The following conclusions may be made:

1) Thermal softening plays an important role in the dynamic scratching of TiAls investigated in the present study by promoting the detachments of developing chip and the pile-ups.

2) The fractures are involved in the dynamic scratch of the TiAls and the roles of these fractures in the chip formation depend on the microstructure of materials and size of scratch groove.

3) Instantaneous specific energy, scratch resistance and scratch hardness are depthdependent to various degrees with each TiAl. With the increasing depth, these quantities mostly experience an abrupt drop, followed by a slow recovery. Within the tested range of groove depth, the specific energy defines the upper bound and the scratch resistance defines the lower bound with respect to the variation of examined quantities.

4) Specific energy and scratch hardness of the TiAls follow the HEM model and the PSR model to a certain extent in the studied range of groove depth; the related model parameters provide an effective approach of characterizing the responses of the TiAls.

5) The scratch hardness and indentation hardness approach each other in the response to the dynamic impact, demonstrating the effectiveness and efficiency of singlegrit pendulum (rotating) scratch for the purpose of characterization.

6) Among the TiAl alloys, Alloy B exhibits the stronger capability of energy dissipation in the material loss or material removal, while Alloy C displays the stronger resistance against the indentation. 


\section{ACKNOWLEDGMENTS}

This research was sponsored by the U.S. Department of Energy, Office of FreedomCar and Vehicle Technologies, as a part of the Heavy Vehicle Propulsion System Materials Program, under contract DE-AC05-00OR22725 with UT-Battelle, LLC. The research was supported in part by an appointment to the Oak Ridge National Laboratory Postdoctoral Research Associates Program, sponsored by the U.S. Department of Energy and administered by the Oak Ridge Institute for Science and Education.

Authors would like to extend their sincere thanks to Caterpiller, Inc. for providing the TiAls for this study, and to Drs. Peter J. Blau and Jun Qu for allowing us to use their laser profilometer. Authors are grateful to Drs. Peter J. Blau, Jun Qu, Paul F. Becher and Jeff A. Jensen for their helpful comments.

\section{REFERENCES}

1. Aust, E, Niemann, H R, Machining of gamma-TiAl, Adv Eng Mater, 1 (1): 53-57 1999

2. Appel F, Brossmann U, Christoph U, Eggert S, Janschek P, Lorenz U, Mullauer J, Oehring M, Paul J. D. H., Recent progress in the development of gamma titanium aluminide alloys, Adv. Eng. Mater., 2 (11): 699-720 2000

3. Yamaguchi, M., Inui, H., Ito, K., High-temperature structural intermetallics, Acta Mater, 48 (1): 307-322 2000

4. Clemens, $\mathrm{H}$, Kestler, $\mathrm{H}$, Processing and applications of intermetallic gamma-TiAlbased alloys, Adv Eng Mater, 2 (9): 551-570 2000

5. Loria, E. A., Quo vadis gamma titanium aluminide, Intermetallics, 9 (12): 997-1001 2001

6. Djanarthany, S, Viala, J C, Bouix, J, An overview of monolithic titanium aluminides based on Ti3Al and TiAl, Mater Chem Phys, 72 (3): 301-319 2001

7. Gerling, R, Clemens, H, Schimansky, F P, Power metallurgical processing of intermetallic gamma titanium aluminides, Adv Eng Mater 6 (1-2): 23-38 2004 
8. Aspinwall, D K, Dewes, R C, Mantle, A L, The machining of gamma-TiAl intermetallic alloys, CIRP Annals-Manuf Tech 54 (1): 99-104 2005

9. Hsiung, L, and Hodge, A., Microstructure and creep properties of TiAl/Ti3Al in-situ composites, DOE Heavy Vehicle Propulsion Materials Progress, FY 2003 Progress Report

10. Booth, A S, Roberts, S G, The brittle-ductile transition in gamma-TiAl single crystals, Acta Mater, 45 (3): 1045-1053 1997

11. Bentley, S A, Mantle, A L, Aspinwall, D K, The effect of machining on the fatigue strength of a gamma titanium aluminide intertmetallic alloy, Intermetallics, 7 (8): 967-969 1999

12. Goken, M, Kempf, M, Nix, W D, Hardness and modulus of the lamellar microstructure in PST-TiAl studied by nanoindentations and AFM, Acta Mater, 49 (5): 903-911 2001

13. Schillinger, W., Zhang, D., Dehm, G., Bartels, A. and Clemens, H., Creep behavior and microstructural stability of lamellar $\gamma$-TiAl (Cr, Mo, Si, B) with extremely fine lamellar spacing, Mat. Res. Soc. Symp. Proc., Materials Research Society, Vol. 646, N1.4.1-N1.4.6, 2001

14. Shazly M, Prakash V, Draper S, Mechanical behavior of Gamma-Met PX under uniaxial loading at elevated temperatures and high strain rates, Int J Solids Struct, 41 (22-23): 6485-6503 2004

15. Wang, H., Subhash, G., Chandra, A., Characteristics of single-grit rotating scratch with a conical tool on pure titanium, Wear, 249: 566-581, 2001

16. Subhash, G., Loukus, J. E., Pandit, S. M., Application of data dependent systems approach for evaluation of fracture modes during a single-grit scratching, Mech. Mater. 34: 25-42, 2002

17. Wang, H., Wereszczak, A. A., Lance, M. J., Effect of grain size on dynamic scratch response in alumina, Proc. $30^{\text {th }}$ Int. Conf. Adv. Ceramics and Composites, Jan. 2227, 2006, Cocoa Beach, FL, USA, Edited by A. Wereszczak and E. Lara-Curzio.

18. Wang, H., Lin, H. T., Wereszczak, A. A., Yang, N. and Jensen, J. A., Specific energy and scratch hardness of gamma titanium aluminides subjected to single-grit pendulum scratching, Proceedings of ICEF 2006, ASME Internal Combustion 
Engine Division 2006 Fall Technical Conference, Nov. 5-8, 2006, Sacramento, CA, USA, ICEF2006-1532.

19. Keoppel, B. J., and Subhash, G., An experimental technique to investigate the dynamic indentation hardness of materials, Experimental Techniques 21 (3): 16-18 1997

20. Keoppel, B. J., and Subhash, G., Characteristics of residual plastic zone under static and dynamic Vickers indentations, Wear 224 (1): 56-67 1999

21. Wang, H., Wereszczak, A. A., Mechanical responses of silicon nitrides under dynamic indentation, Ceram. Eng. Sci. Proc., 26 (2) 275-283, 2005

22. Subhash, G., Bandyo, R., A new scratch resistance measure for structural ceramics, J. Am. Cera. Soc., 88: 918-925, 2005

23. Murray, M. J., Mutton, P. J., and Waston, J. D., Abrasive wear mechanism in steels, J Lubric. Tech., 104, 9-16, 1982

24. Kato, K, Hokkirigawa, K., Kayaba, T., Endo, Y., Three dimensional shape effect on abrasive wear, J. Tribology-Trans. ASME 108: 346-351, 1986

25. Hokkirigawa, K., Kato, K., Li, Z. Z., The effect of hardness on the transition of the abrasive wear mechanism of steels, Wear, 123: 241-251, 1988

26. Kato, K., Wear mode transitions, Scrip. Metal. Mater., 24: 815-820, 1990

27. Mathia, T. G. and Lamy, B., Sclerometric investigation of nearly brittle materials, Wear of Materials 1985, Edited by Ludema, K. C., ASME, New York, pp. 485-490.

28. Bulsara, V. H., Chandrasekar, S. and Farris, T. N., Scratch testing, ASM Handbook, 8, Mechanical Testing and Evaluation, 317-324, 2000

29. Vingsbo, O., Hogmark, S., Single-pass pendulum grooving - a technique for abrasive testing, Wear, 100: 489-502, 1984

30. Bryggman, U., Hogmark, S., Vingsbo, O., Mechanisms of gouging abrasive wear of steel investigated with the aid of pendulum single-pass grooving, Wear 112: 1451621986

31. Liang, Y. N., Li, S. Z., Li, S., Evaluation of abradability of porous seal materials in a single-pendulum scratch device, Wear, 177: 167-173, 1994

32. Liang, Y. N., Li, S. Z., Li, D. F., Li, S., Some developments for single-pass pendulum scratching, Wear, 199: 66-73, 1996 
33. Briscoe, B. J., Delfino, A., Pelillo, E., Single-pass pendulum scratching of poly(styrene) and poly(methylmethacrylate), Wear 225:319-328, 1999

34. Wang, H., Subhash, G., Mechanics of mixed-mode ductile material removal with a conical tool and the size dependence of the specific energy, J. Mech. Phys. Solids, 50: 1269-1296, 2002

35. Wang, H., Subhash, G., An approximate upper bound approach for the single-grit rotating scratch with a conical tool on pure metal, Wear, 252: 911-933, 2002

36. Shaw, M. C., Metal Cutting Principals, Clarendon Press, Oxford, 1983

37. Brookes, C. A., Green, P., Harrison, P. H. and Moxley, B., Some observations on scratch and indentation hardness measurements, J. Phys. D-Appl. Phys. 5: 1284, 1972

38. ASTM International, Standard test method for scratch hardness of materials using a diamond stylus, G 171-03

39. Sheikh-Ahmad, J., and Bailey, J. A., Flow instability in the orthogonal machining of CP titanium, Transaction of the ASME, J. Manufact. Sci. and Eng., 119: 307-313 1997

40. Johnson, K. L., The correlation of indentation experiments, J Mech. Phys. Solids, 18, 115-126, 1970

41. Studman, C J, Moore, M A, Jones, S E, Correlation of indentation experiments , J. Phys. D- Appl. Phys., 10 (6): 949-956 1977

42. Razavi, H A, Kurfess, T R, Danyluk, S, Force control grinding of gamma titanium aluminide, Int. J. Mach. Tools Manuf., 43 (2): 185-191 2003

43. Mulhearn, T. O., and Samuel, L. E., The abrasion of metals: a model of the process, Wear, 5, 478-498 1962

44. Sedriks, A. J., and Mulhearn, T. O., Mechanics of cutting and rubbing in simulated abrasive processes, Wear, 6, 457-466, 1963

45. Sedriks, A. J., and Mulhearn, T. O., The effect of work-hardening on the mechanics of cutting in simulated abrasive process, Wear, 7, 451-459, 1963

46. Malkin, S., Grinding Technology, Theory and Applications of Machining with Abrasives, Soc. of Manuf. Eng., Dearborn, MI 1989 
47. Malkin, S., Hwang, T. W., Grinding mechanism for ceramics, Annuals CIRP, 45: 569-580, 1996

48. Hwang, T. W., Evans, C. J. and Malkin, S., Size effect of specific energy in grinding of silicon nitride, Wear, 225-229, 862-867, 1999

49. Hwang, T. W. and Malkin, S., Upper bound analysis for specific energy in grinding of ceramics, Wear, 231, 161-171, 1999

50. Ma, Q. and Clarke, D. R., Size dependent hardness of silver single crystals, J. Mater. Res., 10, 853-862, 1995

51. Poole, W. J., Ashby, M. F., and Fleck, N. A., Micro-hardness of annealed and workhardened copper polycrystals, Scr. Mater., 34, 559-564, 1996

52. Nix, W. D. and Gao, H., Indentation size effect in crystalline materials: a law for strain gradient plasticity, J. Mech. Phys. Solids, 46, 411-425, 1998

53. Begley, M. R., and Hutchinson, J. W., The mechanics of size-dependent indentation, J. Mech. Phys. Solids, 46(10), 2049-2068 1998

54. Li, H., and Bradt, R. C., The indentation load/size effect and the measurement of the hardness of vitreous silica, J. Non-Crystal. Solids, 146, 197-212 1992

55. Li, H., and Bradt, R. C., The microhardness indentation load/size effect in rutile and cassiterite single crystals, J. Mater. Sci., 28, 917-926, 1993

56. Quinn, J. B., Quinn, G. D., Indentation brittleness of ceramics: a fresh approach. J. Mater. Sci., 32 (16): 4331-4346 1997

57. Stevenson, M., Kaji, M., and Bradt, R. C., Microhardness anisotropy and the indentation size effect on the basal plane of single crystal hematitle, J. Euro. Cera. Soc., 22, 1137-1148, 2002

58. Liu, C. T. and Maziasz, P. J., Microstructural control and mechanical properties of dual-phase TiAl alloys, Intermetallics, 6, 653-661, 1998 